\title{
Missing links, missing markets: Internal exchanges, reciprocity and external connections in the economic networks of Gambian villages*
}

\author{
Dany Jaimovich ${ }^{\dagger}$ \\ Goethe University Frankfurt
}

October 19, 2012

\begin{abstract}
A unique dataset of social and economic networks collected in 60 rural Gambian villages is used to study the ways in which households with links outside the village (that are considered as a proxy for market connections) behave in the locally available exchange networks for land, labor, input and credit. Using measures gleaned from the social network analysis literature, the econometric results at both household and link (dyadic) level provide evidence of: (i) substitutability between internal and external links, and (ii) substitutability between internal reciprocation and external links. These findings provide support for the transformation process of primitive economies described in a long tradition of anthropological work as well as recent theoretical models.
\end{abstract}

Keywords: Social Networks, Missing markets, Gift economy, Economic Anthropology, West Africa.

JEL codes: Z13, C31, 012.

\footnotetext{
*ACKNOWLEDGMENTS TO BE ADDED

$\dagger$ Department of Applied Econometrics and International Economic Policy, Goethe University. RuW Postbox 46, Grüneburgplatz 1, D-60323 Frankfurt am Main. E-mail: jaimovich@econ.uni-frankfurt.de
} 
"The pattern of symmetrical and reciprocal rights is not difficult to understand if we realize that it is first and foremost a pattern of spiritual bonds between things which are to some extent parts of persons, and persons and groups that behave in some measure as if they were things." Mauss (1923, "The Gift")

\section{Introduction}

The aim of the present paper is to contribute to the empirical analysis of the process of transformation in traditional rural societies using a network perspective. A unique database on economic networks (land, labor, inputs and credit) collected in 60 villages of rural Gambia, where traditional non-monetary economic exchanges - gift economy- prevail, is used to study the behavior of households involved in market transactions.

The transition from primitive economic activities to more complex exchanges that eventually lead to market economies or alternative modern economic systems was a relevant element in the structure of theories of the classic economic authors and a key issue for the early economic sociologists, as can be seen in the works of Thorsten Veblen, Max Weber and, in particular, Karl Polanyi. In Polanyi's great transformation, modern societies are shaped in the transition from a network of communitarian reciprocal exchanges to institutionalized market interactions (Polanyi, 1944). The concept of primitive economies as reciprocal exchanges is largely based on Malinowski's influential description of the production system of the Trobriand islanders (Malinowski, 1921, 1922), that is also the foundation for Mauss' analysis of a gift economy.

The transformation process is formalized by Kranton (1996). In her model, agents can choose either reciprocal exchanges with other agents whose preferences, production costs and other relevant characteristics are known, or market transactions with anonymous agents, using money as medium of exchange. If the cost of searching for trading partners is higher than the benefit obtained from consumption diversification offered by markets, then agents will prefer reciprocal exchanges. One of the main results of Kranton (1996) is that reciprocity can be enforced even if markets exist as an alternative for transactions. In particular, Kranton's prediction is that reciprocal exchanges will be pervasive in settings as the Gambian villages, where common features of rural societies are predominant, namely high costs to access market exchanges, long-lived inter-personal relationships (and therefore high value on the future utility of a relationship), and nondiversified consumption.

The descriptions of ethnographic and anthropological literature and the predictions of models a la Kranton (1996) have not been matched with rigorous quantitative evidence about the transformation process. ${ }^{1}$ Most of the empirical evidence of behavior under different levels of market exposure has been collected through experimental games across different societies. A very stable finding, replicated in experiments played in different groups and contexts, is that communities more exposed to market are fairer in trans-

\footnotetext{
${ }^{1}$ A summary of studies regarding the influences of markets on behavior and preferences is provided by Bowles (1998). More related to the framework of the present study, Barrett (2008) reviews the literature related to market participation of smallholders in Africa.
} 
actions with strangers, as measured by the amount of money offered in the ultimatum game and the dictator game (Henrich et al., 2004 and Henrich et al., 2010). Indirectly, this result implies that individuals belonging to groups that participate in the market are less likely to get involved in reciprocated transactions. In other words, the difference between gift and commodity exchange is that a gift establishes a feeling-bond between two people, while a commodity transaction does not (Hyde, 1983).

In the analysis, I will follow Kranton and Minehart (2001) in considering a market as a network of buyers and sellers that establish a link between each other. The data from Gambian villages provide information regarding the existence of a link connecting a particular household for a transaction outside of the village in each network. While most of the households in the data have at least one economic link with their fellow villagers (and in most of the cases several links), only few households have links outside the village. I consider these links outside the village as a proxy for a market connection, an assumption supported by observations on the field and by empirical tests provided below. On the other hand, and in line with previous studies described in next section, the economic links within the village are assumed to represent some kind of gift exchange.

Another important assumption of the study is the idea, first formalized by de Janvry et al. (1991), that the problem of missing or failing markets may be better understood as a household instead of a commodity specific phenomenon. Even if markets exist, transaction costs that exceed the utility gain from the transaction will push a particular household outside of the market. Moreover, there are general equilibrium effects, in which failures of an important market, such as credit, labor or food, can lead to exclusion from exchanges in other markets. While the predictions of de Janvry et al. (1991) are not directly tested, the concept of household-level market exclusion is adopted. ${ }^{2}$

For the empirical analysis, two specific hypotheses stemmed from previous descriptions of the transformation process will be explored: (i) Substitutability between internal and external exchanges, i.e. households with external economic links are less likely to be involved in economic interactions within the village; and (ii) reciprocation versus market, i.e. households with external economic links are less likely to be involved in reciprocated exchanges with fellow villagers. Network based measures of degree centrality (number of links in each network) and reciprocity are used to quantify economic interactions inside the village. The relationship of these variables with external economic interactions is analyzed in various empirical specifications. Firstly, the predicted probability of external link existence is used to implement a propensity score matching estimator to compare a set of households with similar observed characteristics. The analysis at the household-level is expanded by implementing a specification similar to the recent contribution of Banerjee et al. (2012), where variables gleaned from network measures are included into a linear model. Taking advantage of the network structure of the data, the main hypotheses are further tested at the dyadic (link between households) level, following the specification

\footnotetext{
${ }^{2}$ Most of the previous applied econometric studies specifically dealing with the issue of market participation are efforts to test models in the spirit of de Janvry et al. (1991). Goetz (1992) combines bivariate probits and 2SLS in a sample of Senegalese rural households and finds some differences in the determinants of grain market participation for buyers and sellers. Using structural estimation, Key et al. (2000) show the importance of transaction costs in data for Mexican ejidos. Bellemare and Barrett (2006) use an ordered Tobit model to show the sequentiality in the decisions of market entry and volumes to be transacted for rural households in East Africa.
} 
first proposed by Fafchamps and Gubert (2007).

In all the econometric specifications I find support for the main hypotheses. External links are negatively related to household degree, and therefore there is evidence of substitutability between internal exchanges and external links. This effect is observed only within each network and not across networks. In terms of the reciprocation versus market hypothesis, the analysis also provides evidence of less reciprocated exchanges for households with external links, again mainly within each network, but in the case also across some other networks as well. These results are generally robust to the different econometric specifications and alternative methods to control for village and household level unobserved heterogeneity, but the effects are not always present for every network. The findings are suggestive in terms of providing empirical evidence for the hypotheses using detailed network data. However, they should not necessarily be interpreted in causal terms given potential endogeneity problems that might remain unsolved with the techniques that the data allow me to use.

The rest of the paper is structured as follows: Section 2 describes the setting and data collection. In section 3 formal definitions of the network measures are presented. Section 4 presents the main empirical analysis while the last section briefly presents policy implications and concludes.

\section{Context and Data}

\subsection{Setting: economic exchanges in rural Gambia}

The setting of the study largely resembles the characteristics of rural West Africa, with villages mostly engaged in basic subsistence agriculture, combined in some cases with cash crop production -mainly groundnuts, but also some fruits and vegetables in recent years- with the use of basic technologies (Gajigo and Saineb, 2011). Some villages also rely on fishing and pastoralism as complementary economic activities. In the small villages in which the surveys were conducted kinship relationships are very common and are usually dominated by the lineage of the village founders and the oldest settlers. Villagers are organized into compounds, members of the same family living in a group of huts surrounded by a grass fence that organize daily activities together. The majority of labor activities are carried out by compound members organized in one or more dabadas or farm production units (Webb, 1989). Most of the time a compound can be identified as a household, but in some cases there are members identified as independent households inside the compound. ${ }^{3}$

While many of the production activities are organized within the compound, there is also an active exchange with other households in the village, mainly through nonmonetary transactions that can be most of the time classified as a gift economy. As described by Shipton (1990) "In The Gambia, virtually everything is lendable and at times will be lent. This includes nearly all factors of agricultural production land, labor, livestock, seeds, fertilizer, pesticides, and farm tools. Craft tools, vehicles, and household

\footnotetext{
${ }^{3} \mathrm{~A}$ detailed description of the organization of activities within compounds is provided by Carney and Watts (1990) and von Braun and Webb (1989).
} 
goods are also lent". For the present study these exchanges are grouped in four networks -land, labor, inputs (basically tools, seeds and fertilizers), and credit- described in detail below.

Formal land titles are very rare in rural Gambia. Instead, the unwritten rights over land usage are determined by the descendants of the village's founders, generally the village chief (Alkalo) and his direct relatives. In some cases, the kabilo (clan) heads, who might not be related to the founder's lineage but represent the descendants of other early settlers, are entitled to permanent usage rights. As remarked by Webb (1989), the rights over land are closely related to the old social structure, with the former highest castes having the most productive plots. All other villagers must borrow plots on either a seasonal or an annual basis from them, in agreements that can also last for several years (Chavas et al., 2005). Sometimes other individuals own small plots of land outright that can be lent or rented, usually to individuals outside of the village.

In terms of labor exchanges between villagers, to deal with shortage of family workers (particularly before and during the rainy season) households usually invite other villagers or outsiders to help with household tasks in exchange for various kinds of goods, labor or even a marriage arrangement. Other alternatives available in some villages are the use of kafos, organized workforce of villagers from various households who participate in the provision of public goods but who can also be hired for a fixed wage, and the use of strange farmers that provide part-time labor in exchange for the right of use of part of the family plot for their own benefit (Swindell, 1978). In the villages surveyed, the hiring of kafos was rarely observed (less than $1 \%$ of the interviewed households heads declared borrowing labor from more than 5 other households) and the use of strange farmers can not be identified given data limitations.

The input network is defined in the survey as exchanges of means of production that imply a monetary or opportunity cost for the lender, such as tools, cattle, fertilizer, seeds and the like. Cattle are usually lent for milk, manure and transport during long periods, and sometimes also lent to relatives outside the village, as means of avoiding the loss of an entire herd in the case of disease or theft (Shipton, 1990). As for other agricultural inputs, the lending can take the form of a bilateral household exchange or a centrally organized process by some of the villager groups. The external links relate to the acquisition and distribution of these inputs from and to other villages, rural markets or urban centers.

The credit exchanges between villagers generally follow the Islamic prescription of not charging any interest rate to the borrower, and are related to risk-sharing activities of support for relatives and friends, enmeshed in the network of mutual obligations created by the other types of economic and social exchanges (Shipton, 1990). Apart from the direct borrowing of money from another household in the village, there is also the possibility of obtaining credit from external sources, both informal and formal (mainly rural development banks or microcredit agencies), or from some village-level rotating saving and credit associations (ROSCAs), locally known as osusus. Other forms of organized saving, such as the money-keepers and the village bank, are usually available. 


\subsection{Data collection and description}

The data were collected by the author, other researchers, and local collaborators in the context of the baseline survey for the impact evaluation at national level of a CommunityDriven Development Program, conducted between February and May of 2009. 60 Gambian villages with populations between 300 and 1,000 inhabitants, mainly in rural areas (just 4 villages are in semi-urban areas), were randomly selected using area sampling at the ward level, a smaller geographical division that tends to be homogeneous in geographical but heterogeneous in socio-cultural terms.

Given the costs associated with implementing LSMS-type surveys for all households in a village, structured group interviews geared to collect quantitative information were implemented instead. Therefore, village censuses were carried out through gatherings co-organized with the Alkalo and district-level officers. In such village meetings it was possible to obtain relatively coarse quantitative information -with a particular focus on socio-economic interactions- for almost all households in each village (the median villagelevel coverage rate is 94\%.). The survey has two sections: a standard (and very lean) household questionnaire designed to collect a vector of household characteristics and a set of questions specifically designed to understand the economic networks in the village. The respondents were asked to name villagers with whom they had exchanges, during the past year, in terms of (i) land, (ii) labor, (iii) inputs, and (iv) credit. We also collected information about networks created by kinship and marriages and, importanly for the purpose of the present study, about connections external to the village in each of these networks.

We finally interviewed 3,320 persons, but the sample is reduced to 2,810 when incomplete data are removed. In Table 1 the main variables of the household questionnaire are summarized. Average household size is 12.7 members, but some households have even more than 50 members (approximately 1\% of the sample) a fact explained by the polygamous nature of Gambian rural society, with $45 \%$ of households declaring to have more than one wife. Only a very small number of household heads are females $(7 \%)$ or nonMuslims (4\%). $16 \%$ of the respondents declared having some kind of formal education (although a substantial fraction of the villagers received some kind of koranic education and usually master basic Arabic language skills) and the average (self-declared) annual income per capita is 3,565 Gambian Dalasis, which corresponds to approximately $\$ 380$ (in constant 2005 and PPP adjusted dollars from World Development Indicators), with only around $12 \%$ of this income stemming from agricultural activities. Around half of the respondents declare having current or former household members who work outside the village, including $19 \%$ who receive remittances from overseas migrants outside Africa. $41 \%$ declare to produce some sort of cash crops.

Table 2 presents descriptive statistics for the data on networks, that are analyzed in detail below. Meanwhile, it is important to highlight that these data support the idea that most of the economic interactions take place within the village instead of outside it. When the four economic networks are taken together (fifth row of Table 2), it can be seen that $76 \%$ of the households do not have any links to bring something from outside the village and $83 \%$ do not have links to send something outside the village (columns 3 and 4 respectively). On the other hand, only less than $15 \%$ of the households declared 
to have no links in these networks with fellow villagers (internal autarky).

More details related to the data collection methodology, as well as an extensive analysis of the data can be found in Jaimovich (2011).

While this database is unique in many aspects, there are limitations that constrain the possibilities of the empirical analysis. In first place, the data are available only for one period, therefore present the restrictions of cross-sectional analysis. In particular, dynamic features in household's behavior can not be captured, limiting the observed economic interaction inside and outside the village to those that have taken place in the year before the survey. Another issue with the data is that the relevant unit for economic exchanges is the household, therefore the complexities of intra-households allocation of resources are not captured and the external exchanges of others members apart from the household head can be misrepresented.

\section{Definitions: Network measures.}

\subsection{Internal exchanges}

Each household will be considered as a node $i$ in each of the $m$ economic exchange networks, with $m=\{L A N D, L A B O R, I N P U T, C R E D I T\}$. The internal exchanges consist of a set of nodes in each village $v$ belonging to $n_{v}=1, \ldots, N_{v}$ where $n_{v}$ is the number of households inside each village. The existence of a link between households $i$ and $j$ in the network $m$ will be measured as a binary variable:

$$
\ell_{i j}(m)=1 \text { if a link is reported in the data, } \ell_{i j}(m)=0 \text { otherwise. }
$$

where $\ell_{i j}(m)$ is a directed link from $i$ to $j$, which implies that the former lends $m$ to the latter. If the opposite is true $\left(i\right.$ borrows from $j$ ), then the link will denoted as $\ell_{j i}(m)$.

Given this definition, the internal exchanges will consider the existence of a link but not the intensity of the exchange, because this information is not available. In other words the analysis concentrates on the extensive rather the intensive margin of economic exchanges.

While the data do not provide information in terms of the specific type of exchange that a link implies, I will consider that a link in the network of internal economic exchanges represents some kind of gift exchange, an assumption that is largely supported by the description of the economic activities presented in section 2.1, as well as the anecdotal observations during the field work.

A basic metric of the level of internal exchanges of a node $i$ in a network $m$ is its degree centrality, $d_{i}(m)$, measured as the number of links involving this particular node. In the data it is possible to make a distinction in terms of the directionality of the link. If

\footnotetext{
${ }^{4}$ Jaimovich (2011) is a chapter of my PhD dissertation, versions of which have also been circulated as an unpublished working paper, where some of the results discussed in the present paper are also reported.
} 
the link goes from $i$ to $j$, then it will be counted in the measure of the out-degree. Formally:

$$
\text { Out-degree: } d_{i}^{\text {out }}(m)=\sum_{j} \ell_{i j}(m) \text {. }
$$

In the economic networks, the out-degree of $i$ is related to its position as a lender. When the link goes in the other direction, from $j$ to $i$, it will be counted as part of the in-degree of $i$ :

$$
\text { In-degree: } d_{i}^{i n}(m)=\sum_{j} \ell_{j i}(m) \text {. }
$$

For economic networks the in-degree is a characteristic of $i$ as borrower.

The first panel of Table 2 presents descriptive statistics for the average degree of the households in the sample, both as borrowers and as lenders. The average degree for the economic networks is always below 1, indicating that for many households $d_{i}(m)=0$ (internal autarky). This fact is captured in the fourth panel of Table 2, which indicates that between $40 \%$ and $50 \%$ of the households do not have any links for each specific network. Among the networks, INPUT has households with higher degree and CREDIT with lower, but these differences are not statistically significant given the large variation in the distribution of degrees.

\subsection{Reciprocity}

One of the main characteristics of tribal economies, as described by Malinowski (1921) and Mauss (1923), is the reciprocity of exchanges. Reciprocity can be defined in various ways, but basically is linked to the concept of non-pecuniary transactions in which the provision of a good or service is expected to be rewarded in the future. This reciprocity can be expected in the long term, particularly in villages like those of the present study, where social relations are long-lived. This is a limitation for the cross-sectional data used in the empirical analysis, but at least it is possible to observe if an economic exchange was reciprocated within the year before the survey was conducted.

I will limit to the description of reciprocity within the $m$ economic networks for which detailed information is available. Given that the data about links are directed, it is possible to observe whether any specific link has a counterpart in the opposite direction. If a link is bidirectional, meaning that the lender also was a borrower in a transaction with a given household, this link will be considered as reciprocated. In particular:

$$
\operatorname{Recip}_{i j}(m)=1 \Leftrightarrow \ell_{i j}(m)=1 \text { and } \ell_{j i}=1
$$

where $\ell_{j i}$ is a link between $i$ and $j$ in any of the $m$ networks. Therefore, reciprocation can exist within the same network (e.g. reciprocating input borrowing with input lending) or with another network (e.g. reciprocating input borrowing with land lending).

As in the case of household degree, the reciprocal relation is directional. For each household $i$, reciprocal out - degree is defined as: 


$$
\operatorname{Recip}_{i}^{\text {out }}(m)=\sum_{j} \ell_{i j}(m) \ell_{j i}
$$

Similarly, reciprocal in - degree is defined as:

$$
\operatorname{Recip}_{i}^{i n}(m)=\sum_{j} \ell_{j i}(m) \ell_{i j}
$$

The second panel of Table 2 shows a general description of the reciprocal degree of households in the sample, taken as a percentage of household's degree in each network. INPUT is the network with more reciprocation, with an average of around half of the links, followed by $L A B O R$, where nearly $35 \%$ of the links are reciprocated. In the case of $L A N D$ and CREDIT, approximatelly only $20 \%$ of the links are reciprocated on average.

\subsection{External connections}

The existence of an external link in each of the $m$ economic networks is reported in the data, but not the identity and location of the agent with whom villagers have it. Neither the intensity of the link nor the existence of more than one external link in each network are reported. Given these limitations of data, the external link will be taken as a binary variable:

$$
\operatorname{Ext}_{i}(m)=1 \text { if an external link is reported, and } \operatorname{Ext}_{i}(m)=0 \text { otherwise. }
$$

Given this, and in a similar fashion as in the case of internal exchanges, the analysis will capture the effect of external connections at the extensive instead of the intensive margin. A distinction will be made in terms of external links created to bring something to the village $\left(\operatorname{Ext}_{i}^{i n}(m)\right)$ or to give out something from the village $\left(\operatorname{Ext}_{i}^{\text {out }}(m)\right)$.

Even though the specific characteristics of the external connection can not be identified in the data, I will consider the external links as a proxy for a link to a market outside the village. The idea is that economic exchanges outside the village are more likely to be established between anonymous agents, with the purpose to expand the available set of production inputs or diversify consumption, and, even if no money is used as medium of exchange, involving relative prices agreed by the agents. This assumption is supported by the evidence presented below, given household-level variables such as number of emigrants, remittance reception, and marriages with outsiders are uncorrelated with the probability of having an external link. On the other hand, households involved in the production of cash crops are more likely to have external connections. Informal interviews in the field as well as reports provided by the local enumerators also confirm that this assumption is likely to be true.

In the third panel of table $2 \operatorname{Ext}_{i}(\mathrm{~m})$ is summarized. Only $24 \%$ of the households have an external-in link and $17 \%$ an external-out in any of the four economic networks (fifth row of table 2). In the case of $L A N D, 5 \%$ of the households give out plots to outsiders, while $8 \%$ get land from other villages. For $L A B O R$, the database has information only about the households with members working outside the village. ${ }^{5}$ Just $3 \%$

\footnotetext{
${ }^{5}$ Not having information related to external hiring is unfortunate, because the use of strange farmers is an important way to deal with labor shortages (Swindell, 1978). In terms of the definition of households
} 
of the households work outside the village. For the links in the INPUT network, $8 \%$ of the respondents declared getting input from outsiders, just $3 \%$ to give out. A similar disproportion is observed for CREDIT, where $12 \%$ obtained money from outside the village and just $5 \%$ acted as money lenders.

\section{Empirical analysis}

\subsection{Empirical strategy}

The main goal of the empirical analysis is to test the transformation process of rural economies that are exposed to the possibility of more complex types of exchanges outside of the village. Using the detailed database about network of economic exchanges described above, two hypotheses of the transformation process will be tested: (H1) Households with external economic links are less likely to be involved in economic interactions within the village (substitutability between internal and external exchanges); and (H2) Households with external economic links are less likely to be involved in reciprocated exchanges with fellow villagers (reciprocation versus market hypothesis).

The network measures to be used in the analysis have been described in last section. External economic interactions are measured with the binary variable $\operatorname{Ext}_{i v}(m)$, which takes value 1 if a household declared to have an external link in network $m$, zero otherwise. The main dependent variable used to test $H 1$ is the household-level degree centrality in each network, $d_{i}(m)$, which measures the level of economic interactions within the village. In the case of H2, the level of reciprocal exchanges is quantified with the reciprocal degree $\left(\operatorname{Recip}_{i}(m)\right)$.

It is to be expected that households with external links are different to those that do not have external connections. In order to understand what the household-level characteristics related to the the probability of $\operatorname{Ext}_{i v}(m)=1$, the following model is estimated:

$$
\operatorname{Pr}\left(\operatorname{Ext}_{i v}(m)\right)=G\left(\alpha_{v}+X_{i v} \beta_{x}\right)
$$

where the dependent variable can be a link to bring something to the village $v$ $\left(\operatorname{Ext}_{i v}^{i n}(m)\right)$ or give out something/someone outside $\left(\operatorname{Ext}_{i v}^{\text {out }}(m)\right)$. In addition to the probability of an external link in each of the $m$ networks, the probability of an external link in any of the economic networks will be estimated. $G(\cdot)$ is the logistic function and $X_{i v}$ is a vector of controls at the household level. To control for village level unobserved heterogeneity, in all the estimations, village fixed-effects are included $\left(\alpha_{v}\right){ }^{6}$

In order to test $H 1$ and $H_{2} 2$ in a set of household with comparable observable characteristics, the predicted values from Equation 1 are taken as propensity scores to match

working outside the village, the original question was "Did you, or any members of your household, work for other households during the last year (2008-9)? If yes, how many days?". Only households that worked at least one week during last year outside the village are considered as having an external link.

${ }^{6}$ Given the dependent variable is binary, the coefficients can suffer the incidental parameters problem. One alternative to solve this problem is the use of the conditional likelihood function estimator, that in this case will take the form $L=\prod_{v=1}^{60} \operatorname{Pr}\left(\frac{E x t_{1 v}, \ldots, E x t_{n v}}{\sum_{i=1}^{n} E x t_{i v}}\right)$. In the Appendix (Table A.1) is shown that estimating Equation 1 with this specification barely change the results, dismissing this concern. 
households with similar probability of having an external link. Taking $p_{i}$ the propensity score for an external link, for each $i$ with $E x t_{i}=1$ the comparison group $C(i)$ is created using the nearest-neighbor matching estimator (Becker and Ichino, 2002):

$$
C(i)=\min _{j}\left\|p_{i}-p_{j}\right\|
$$

only for the households without external links that are in the common support of the propensity scores $\left(\operatorname{Ext}_{j}^{c s}(m)=0\right)$. The standard errors are bootstrapped to take into account that values are estimated. For the main results, the 3 nearest-neighbor matching estimator is reported. ${ }^{7}$

If the creation of an external link is completely determined by the observable household characteristics included in Equation 1, then the results for the matching estimators can be taken as the causal estimate of the average treatment effect of $\operatorname{Ext}_{i}(m)=1$ on household's degree and reciprocal degree. Nevertheless, it is difficult that the unconfoundedness assumption holds in this case, given unobservable household characteristics are likely to jointly determine the dependent variables as well as the existence of a external link. Given this concern, the results must interpreted as the differences in $d_{i}(m)$ and $\operatorname{Recip}_{i}(m)$ for a set of households with and without external links that are comparable according to observable characteristics.

To further analyze $H 1$ at the household-level, I will follow Banerjee et al. (2012), in their the reduced-form specification, by using measures of network centrality in a linear specification of the following form: ${ }^{8}$

$$
\frac{d_{i v}(m)}{n_{v}-1}=\alpha_{v}^{m}+X_{i v} \beta_{x}^{m}+\operatorname{Ext}_{i v}(m) \beta_{e x t}^{m}+e_{i v},
$$

where the dependent variable, household's degree, is expressed in terms of the total possible links that a household can have in each village $v .{ }^{9}$ Village level fixed-effects $\left(\alpha_{v}\right)$ are included, as well as the vector of household-level characteristics, $X_{i v}$ already described above. $e_{i v}$ is the disturbance term (clustered at village level). The vector of coefficients of interest is $\beta_{e x t}^{m}$, associated with the dummies capturing the existence of an external link in each network $m\left(\operatorname{Ext}_{i v}(m)\right)$. In particular, if there is substitutability between $d_{i v}(m)$ and $\operatorname{Ext}_{i v}(m)$, it is expected that $\beta_{e x t}^{m}<0$.

If $\operatorname{cov}\left(\operatorname{Ext}_{i v}(m), e_{i v}\right)=0$ and $\operatorname{cov}\left(X_{i v}, e_{i v}\right)=0$, then estimating Equation 3 with OLS will yield $\beta_{e x t}^{m}$ that are consistent estimators of the effect of external links on the degree of internal exchanges. Nonetheless, as mentioned above, it is likely that household unobserved characteristics are related with the existence of links in both internal and external networks, and therefore $\operatorname{cov}\left(\operatorname{Ext}_{i v}(m), e_{i v}\right) \neq 0$. If $\mu_{i}$ denote household level

\footnotetext{
${ }^{7}$ If different number of nearest-neighbors are used or if the kernel matching estimator is implemented instead, the results (available upon request), even though different in magnitude, have a similar interpretation.

${ }^{8}$ Banerjee et al. (2012) use the eigenvector centrality in their study of microfinance diffusion in Indian villages, and show that their results are different if degree centrality is used instead. This is the case given their data are for (subsamples) of networks with many more nodes than the network data from Gambian villages. Given networks are much smaller for the latter, and therefore indirect connections are not so relevant, eigenvector and degree centrality are very similar (Borgatti, 2005).

${ }^{9}$ If instead $d_{i v}(m)$ is used as dependent variable, the main results are unchanged.
} 
unobservable characteristics, then the disturbance term in Equation 3 can be re-written as:

$$
e_{i v}=\mu_{i} \sigma+u_{i v},
$$

where $u_{i v}$ is iid. In the case when $\operatorname{Ext}_{i v}(m)$ is one variable (to avoid assumptions related to the covariances within $\operatorname{Ext}_{i v}(\mathrm{~m})$ when taken as a vector), if the usual OLS assumptions hold (including $\left.\operatorname{cov}\left(X_{i v}, e_{i v}\right)=0\right)$ and $X_{i v}$ relates to $\operatorname{Ext}_{i v}(m)$ only through its relationship with unobservables, then plim $\widehat{\beta_{e x t}^{m}}=\beta_{\text {ext }}^{m}+\sigma \frac{\operatorname{cov}\left(E x t_{i v}(m), \mu_{i}\right)}{\operatorname{var}\left(\operatorname{Ext}_{i v}(m)\right)}$. Therefore, if it is expected that $\mu_{i}$ will affect degree and external links in the same direction ( $\sigma$ and $\operatorname{cov}\left(\operatorname{Ext}_{i v}(m), \mu_{i}\right)$ have the same sign), for example through entrepreneurial ability, empathy or assiduousness, then $\widehat{\beta_{e x t}^{m}}$ will be upward biased. In this case, if in the estimation of Equation $3 \widehat{\beta_{e x t}^{m}}<0$ is obtained, then $\beta_{e x t}^{m}$ is indeed negative and the coefficient obtained is an upper bound of its true magnitude. It is more difficult to think in cases when it is expected that $\mu_{i}$ affects internal and external exchanges in opposite directions (maybe some kind of asymmetric information problem in which villagers know that $i$ is dishonest but people outside do not), but if this is the case then $\widehat{\beta_{e x t}^{m}}$ will be downward biased and when negative coefficients are found it is not possible to know if the sign is only due to the bias or not.

Ideally, an instrumental variable will be used to deal with this potential endogeneity problem, but it is extremely unlikely to find in the data a household level variable $z_{i}$ that will credibly meet the requirements of $\operatorname{cov}\left(z_{i}, e_{i v}\right)=0$ and $\operatorname{cov}\left(z_{i}, \operatorname{Ext}_{i v}(m)\right) \neq 0$. Household-specific random effects are not feasible either, because the likely endogeneity of the external links implies that it will be correlated with the random effects. Therefore, if the expected result $\left(\beta_{e x t}^{m}<0\right)$ is obtained, its sign can be interpreted in a causal way only if the assumption of unobservable characteristics to be related with internal and external exchanges in the same direction holds.

In the same spirit of Equation 3, the relationship of reciprocation and external connections (H2) is tested using the following specification:

$$
\frac{\operatorname{Recip}_{i v}(m)}{d_{i v}(m)}=\alpha_{v}^{m}+X_{i v} \beta_{x}^{m}+\operatorname{Ext}_{i v}(m) \beta_{e x t 2}^{m}+e_{i v},
$$

where the dependent variable is the proportion of reciprocated links over the total links of households $i$ in network $m$. The same concerns in terms of the endogeneity of the external links variables are valid here, and the coefficients must not necessarily be interpreted in a a causal way. If $\mu_{i}$ is positively correlated with both $\operatorname{Recip}_{i}(m)$ and $\operatorname{Ext}_{i v}(m)$ (and the other assumptions stated above also hold), then the expected $\widehat{\beta_{\text {ext } 2}^{m}}<0$ will be an upper bound of the true unbiased value. If the opposite is true, the sign can just be driven by the inconsistency of the estimators. ${ }^{10}$

\footnotetext{
${ }^{10}$ Another potential concern with the estimation of Equations 3 and 5 is the fact that the dependent variable is a fraction that can take values between 1 and 0 . To check if this pose a problem to the estimation, I will follow Papke and Wooldridge (2008) in estimating the equation as a probit by quasimaximum likelihood and controlling village unobserved heterogeneity by using the Mundlak-Chamberlain device, therefore instead $\alpha_{v}$ the average of all the village-variant variables $\left(\overline{X_{v}}\right.$ and $\left.\overline{E x t_{v}}\right)$ are included. In Tables A.3 and A.5 of the Appendix the results of this model are displayed, and it is possible to results, particularly in terms of the sign of $\beta_{\text {ext }}$, are the same as in the main specification.
} 
An alternative way to control for unobserved household characteristics is to take advantage of the network structure of the data, where every household $i$ can have links with many fellow villagers $j$ and therefore it is possible to include household fixed effects. In the case of $H 1$, the formation of a link $\ell_{i j}(m)$ with a fellow villager is estimated using the following dyadic model:

$$
\ell_{i j v}(m)=G\left(\alpha_{i}+w_{i j v} \beta_{d y a d}+\operatorname{Ext}_{i j v} \beta_{\text {extdyad }}+\left(X_{i v}+X_{j v}\right) \beta_{\text {sum }}+\left|X_{i v}-X_{j v}\right| \beta_{d i f}\right)
$$

where the dependent variable is the undirected binary measure of a link between $i$ and $j$ (therefore in this case $\left.\ell_{i j v}(m)=\ell_{j i v}(m)\right) .{ }^{11}$ To preserve symmetry on the righthand-side, I follow Fafchamps and Gubert (2007) by specifying: $\beta_{\text {dif }}$ as the coefficient associated with the absolute value of the difference in attributes between $i$ and $j$ and $\beta_{\text {sum }}$ to the sum of their attributes (for variables like household size, head's age, income, etc.), and $\beta_{\text {dyad }}$ as the parameter associated with the variable $w_{i j v}$ that corresponds to common characteristics of $i$ and $j$ (like kinship and ethnic group). As for the coefficient associated with $\operatorname{Ext}_{i j v}\left(\beta_{\text {extdyad }}\right)$ two kinds of dummies are included: One $\operatorname{Ext}_{i j}(m)$ when only one household in the dyad has an external link, and Two Ext $t_{i j}(m)$ when this is the case for both (therefore the comparison group is dyads without external links). ${ }^{12}$

Including $\alpha_{i}$ directly in equation 4.1 may imply the potential problem of incidental parameters, namely the inconsistency in the estimation of the household fixed effects can be 'transmitted' to inconsistency in the estimation of the other parameters. One alternative to deal with this issue is the estimation of the conditional likelihood function, as proposed by Chamberlain (1980), that in this case will take the following form:

$$
L=\prod_{i=1}^{n_{v}} \operatorname{Pr}\left(\frac{\ell_{1 j v}(m), \ldots, \ell_{n_{v} j v}(m)}{\sum_{j=1}^{n_{v}} \ell_{i j v}(m)}\right),
$$

that can be estimated only for the sub-sample of households where $\sum_{j=1}^{n_{v}} \ell_{i j v}(m) \neq 0$, therefore those with at least one link in each network.

Even individual household characteristics (including unobservables) are controlled for in this model, it can not be ruled out that in the dyadic specification household-pair-level unobservables are still introducing a bias in the estimates.

In the case of $H 2$, the dyadic model will take the following form:

$$
\operatorname{Recip}_{i j v}=\alpha_{v}+w_{i j v} \beta_{d y a d}+\operatorname{Ext}_{i j v} \beta_{\text {ext } 2}+\left(X_{i v}+X_{j v}\right) \beta_{\text {sum }}+\left|X_{i v}-X_{j v}\right| \beta_{\text {dif }}+\epsilon_{i j v}
$$

where $\operatorname{Recip}_{i j v}=1$ if households $i$ and $j$, from village $v$, have a reciprocated link, and Recip $_{i j v}=0$ if the link between $i$ and $j$ is non-reciprocated. This specification differs

\footnotetext{
${ }^{11}$ The directed probability of link formation can also be estimated, but given the interest in this case is to study the existence of an economic exchange within the village, the undirected measure has a more direct interpretation

${ }^{12}$ In these estimations, the disturbance terms are allowed to be correlated across observations involving the same individual using the two-dimensional clustering methodology proposed by Cameron et al. (2011)
} 
with respect to Equation 4.1 because all dyads without a link (that represent around $99 \%$ of the sample) are not considered. Otherwise, the right hand side variables are all symetric and expressed in a similar fashion as in the dyadic Equation 4.1. Particularly relevant is the fact that $w_{i j v}$ variables, including kinship, are controlled for, given the evidence from Table 10 that most reciprocate exchanges are within the extended family.

Unfortunately, given very small within household variation in terms of the partners, it is not possible to estimate Equation 8 using the conditional likelihood in the spirit of Equation 7 to control for household specific unobservables.

I now proceed to present the results for the different models.

\subsection{Who has external connections?}

The data described in Table 2 shows that few villagers have external links. Who are these villagers? The results of the estimation of Equation 1 are presented in Table 3, where only variables that are interesting from an economic perspective and which are statistically significant are shown. Household size is positively associated with the existence of an external link for most networks. The level of education of the household head is negatively correlated with external links in some networks. For instance, the result in column 5 suggests that educated individuals are less likely to work outside the village, a result that can be explained by the fact that those who have the comparative advantage of basic education inside the village tend to work there. Income per capita increases the probability of external exchanges just in terms of credit. Ethnic minorities (in this case considered as those that represent an ethnic group which constitutes less than a third of villages' population) are more likely to get land and work outside the village. Older households are less likely to give credit.

Traditional roles are very important in rural Gambia, reflecting the importance of social norms. The Alkalo is more likely to lend land and inputs outside the village and the members of the Village Development Council (VDC, an important organization that coordinates the most important village groups) also have a higher chance of exchanging land and receiving credit from outside. Nevertheless, households that are relatives of the Alkalo are less likely to be involved in external credit, a fact probably related to their favorable position for access to cash inside the village. The Imam, village religious leader, is less likely to work outside the village but has a higher probability to give out inputs.

The results in Table 3 provide support to the idea that the external links in the four economic networks are a proxy for market exchanges. All the variables measuring the existence of relatives and friends outside the village -as is the case for number of emigrants, the reception of remittances and marriage exchanges outside the village (to bring and send family members)- are either statistically insignificant or have a negative coefficient as determinants of the probability of an external link. ${ }^{13}$ Additionally, households that produce some kind of cash crops, and therefore that are more likely to be involved in market exchanges, have indeed a higher probability to have an external link (even though

\footnotetext{
${ }^{13}$ The only exceptions are for input given out in the case of the coefficient for $\operatorname{Ext}_{i v}^{\text {in }}(M A R R I A G E)$ and labor for the coefficient of $\operatorname{Ext}_{i v}^{\text {out }}(M A R R I A G E)$
} 
not always statistically significant).

\subsection{The relationship between internal and external exchanges}

In this section I concentrate on the relationship between internal and external exchanges as expressed in $H 1$.

In the descriptive statistics of Table 2 it can be seen that there is no statistical difference in terms of internal autarky $\left(d_{i}(m)=0\right)$ between households with and without external links. But this general comparison can hide a great deal of network and household heterogeneity. Table 4 shows the differences in $d_{i}^{i n}(m)$ and $d_{i}^{\text {out }}(m)$ between households that have external links in any of the four networks $\left(E x t_{i}=1\right)$ and those that do not have it $\left(E x t_{i}=0\right)$. The rows labeled as simple show the average degree and a t-test of the difference between both kinds of households. It can be seen that the differences are statistically significant in various networks, but no clear trend is observed in terms of which kind of household has higher degree. For instance, in the case of Ext $t_{i}^{\text {out }}$, the in-degree is higher on average for households without external links for $L A N D$, while the opposite is true for $L A B O R$ and INPUT.

Given that households with and without external links are very unlikely to be directly comparable, I attempt to create a better comparison group using the observable household characteristics using the matching estimator described in Equation 2. In the rows labeled as matched of Table 4 the difference between the average degree for the groups of households with $E x t_{j}^{c s}=1$ and the estimated comparison group is shown. It is possible to see that when the estimated comparison group is used, all the differences in the internal degree become statistically insignificant.

In a similar fashion as in Table 4, Table 5 compares the degree of households with external links in each individual network $\left(\operatorname{Ext}_{i}(m)=1\right)$ with both the observed and the estimated comparison group of households without external links in that particular $m$ network $\left(\operatorname{Ext}_{i}(m)=0\right)$. The degrees reported in Table 5 are just those of the network $m$ (for instance, when $\operatorname{Ext}_{i}(L A N D)$ is analyzed, just the differences in $d_{i}(L A N D)$ are reported in Table 5). Interestingly, in this case many of the differences in degree are negative and statistically significant for both the simple and matched groups. This the case for when the degree as borrower $\left(d_{i}^{i n}\right)$ is considered. On the other hand, when the differences in degree for networks others than the one with external degree are considered, no significant results are found when the matched groups are compared (Appendix Table A.2).

The results in Table 5 provide initial evidence of substitutability between internal exchanges and external connections, but only in the case of internal borrowers and only for degree within the same network $m$ with the external link $\operatorname{Ext}_{i}(m)$.

An alternative technique to explore $H 1$ at the household-level is the model present in Equation 3. The estimates using OLS are presented in Table 6, where just the values for $\beta_{\text {ext }}$ are reported. In the upper panel, $\operatorname{Ext}_{i v}(m)$ is defined as only one variable, taken value 1 if there is an external link in each particular network, while in the lower panel 
$\operatorname{Ext}_{i v}(m)$ is the vector of all possible external links in all networks $m$. The results in Table 6 are very much in line with those obtained from the comparison of matched samples in Table 5: external links are negatively related to household's internal degree within each network $m$ in many cases, and unrelated with degree in the other networks (with three exceptions out of forty possible for the former). $\beta_{\text {ext }}$ is negative for $L A N D$, except in the $\operatorname{Ext}_{i}^{\text {out }}(L A N D)-d_{i}^{\text {out }}(L A N D)$ combination, for $L A B O R$ only in the $\operatorname{Ext}_{i}^{\text {out }}(L A B O R)$ $d_{i}^{\text {out }}(L A B O R)$ combination, for INPUT always except in $\operatorname{Ext}_{i}^{\text {out }}\left(\right.$ INPUT)- I $_{i}^{\text {out }}($ INPUT $)$ and for $C R E D I T$ only in $\operatorname{Ext}_{i}^{i n}(C R E D I T)-d_{i}^{i n}(C R E D I T)$. Given the average $\frac{d_{i v}(m)}{n-1}$ is around 0.01 in most of the networks, the existence of external links is associated to a reduction on internal degree that ranges between $4 \%$ and $9 \%$.

Given potential endogeneity problems, the magnitudes of $\beta_{e x t}^{m}$ in Table 3 must be taken as the conditional correlation between internal degree and external connections, and its sign can only be interpreted in causal terms under the assumptions stated above.

Going from the household to the link-level, the results the estimation of Equation 4.1 (only for $\beta_{\text {extdyad }}$ ) are presented in Table 7 . The conditional likelihood function (DYADIC CONDITIONAL LOGIT) is compared with a direct logit estimation (DYADIC LOGIT), including village dummies in the latter. It can be seen that, even the sample size is not the same, both models yield very similar results. In the case of $L A N D$ and INPUT, the probability of a link is a decreasing function of the external links within each network (but not statistically significant in the case of One $\operatorname{Ext}_{i j}^{\text {out }}(m)$ ). This is not the case for $L A B O R$ and $C R E D I T$. In this dyadic specification, it is also possible to see more crosseffects between networks, given $\beta_{\text {extdyad }}$ for other networks than $m$ are also significant in various cases. ${ }^{14}$

It is not possible to directly compare the results from the household-level model of Equation 3 and the dyadic model, but the fact that the negative effect of external links on internal economic interaction is present in both specifications provides further evidence that omitted household-level unobserved characteristics do not necessarily driven the results. Nonetheless, it can not be ruled out that in the dyadic specification householdpair-level unobservables are introducing biases in the estimates.

\subsection{Reciprocation versus market}

In this section the focus is on H2, namely, under the presence of market connections (i.e. external links) the reciprocal exchanges that characterize traditional economic relations will tend to be reduced.

In Table 8 a similar procedure as in tables 4 and 5 of the last section is followed. The differences in reciprocal out - degree $\left(\operatorname{Recip}_{i}^{\text {out }}(m)\right)$ and $i n-\operatorname{degree}\left(\operatorname{Recip}_{i}^{\text {in }}(m)\right)$ are compared between households with and without external links, in both the simple and the estimated comparison group $(C(i))$. As it was the case of Table 4, the upper panel of Table 8 shows that no significant differences are found when $E x t_{i}$, a link in any network, is considered (only the results for reciprocal degree any all networks are reported, but

\footnotetext{
${ }^{14}$ There are 2,828 links for $L A N D, 3,546$ for $L A B O R, 5,401$ for INPUT, and 2,598 in the case of CREDIT.
} 
also no significant differences are obtained when reciprocal degree in each network $m$ is considered). This is in contrast to the results of the lower panels of Table 8, where again it is possible to see that the differences are significant when reciprocation within the same network with the external link is analyzed. In the case of Ext $t_{i}^{i n}$, most of the differences are significant or close to significant and always negative. In the case of Ext $t_{i}^{\text {out }}$, only the difference for $\operatorname{Recip}_{i}^{\text {out }}(L A B O R)$ is significant, and also negative. When it comes to the differences in $\operatorname{Recip}_{i}(m)$ for networks others than the one with the external link, again no significant results (with very few exceptions) are found, as reported in Appendix Table A.4.

The results in Table 8 are a first evidence of the reduction in reciprocity under the influence of external connections, particularly when used to bring something to the village. Nevertheless, the same concerns as above in terms of the interpretation of the result are valid here.

The results of the OLS estimation of Equation 5 (only for $\beta_{e x t}^{m}$ ) are reported in Table 9. Apart from the estimation of $\operatorname{Recip}_{i}^{\text {out }}(m)$ and $\operatorname{Recip}_{i}^{\text {in }}(m)$, the proportion of total reciprocated links over total degree, Recip ${ }_{i}$, is also reported in the third column of each network. The preliminary evidence from Table 8 is partially reproduced here. For $L A N D$ and CREDIT, $\beta_{\text {ext } 2}$ is negative for $\operatorname{Ext}_{i v}^{i n}(m)$, but for $L A B O R$ and INPUT the opposite is true, with statistically significant $\beta_{\text {ext } 2}<0$ when $\operatorname{Ext}_{i v}^{\text {out }}(m)=1$. In the specification of $\operatorname{Ext}_{i v}^{i n}(m)$ as the vector of all possible external links (lower panel of Table 9), it can be seen that there are some cross-networks effects of external links, given that some of the coefficients for networks others than the dependent variable are statistically significant, always with negative sign (excepts for $\operatorname{Ext}_{i v}^{\text {out }}(C R E D I T)$ in $\left.L A N D\right)$.

Aggregating reciprocation data to the household level hides important link-level heterogeneity. Table 10 presents a detailed summary of all the links registered in the four economic networks, with particular attention to the fact if the link was reciprocated or not $\left(\operatorname{Recip}_{i j}(m)\right)$. The information is disaggregated according to: whether the household that formed the link has external links or not; whether each link was formed to borrow out or lend in within the village economic networks; and whether the link was established between households that are close relatives (family) or not. Around $65 \%$ of the links described in Table 10 are formed by households that do not have any external link $\left(\operatorname{Ext}_{i}(m)=0\right)$. These households also have more reciprocated links. When links with all the villagers are considered, households without external links reciprocate around half of the links while those with external links just reciprocate between $41 \%$ to $43 \%$. The only exception are households that are external lenders and internal borrowers, which display even more reciprocity than those exchanging just internally (53.5\%). When links are divided between exchanges within and ouside the family, it is possible to see that the differences in reciprocity are mainly associated with the former group. Links with relatives are reciprocated more than half of the time, but more intensively for households with only internal links. On the other hand, the level of reciprocation is similar for all groups if links with non-relatives are considered.

In Table 11 the link summary is presented by network. The external links are considered just in the case a household has links outside the village in each particular network m. LAND and CREDIT are reciprocated in less than $30 \%$ of the cases on average, while 
$L A B O R$ and INPUT have reciprocation in around half of the links. The latter networks are actively reciprocated within the same network, among them and also with $L A N D$ and $C R E D I T$. In terms of the differences between links created by households with and without external links, the previous evidence is confirmed in various combinations: links created by the former group are, in general, reciprocated less. This is particularly the case when the external link is created to bring something to the village, and the effects are more pronounced for the $L A B O R$ and INPUT networks.

To further explore $H_{2}$ at the link level (therefore considering the characteristics of the dyad partner), Table 12 displays the coefficients obtained for $\beta_{\text {ext } 2}$ in the dyadic model of Equation 8. Some of the findings obtained for the household-level results in Equation 5 are confirmed at the link-level. For various specifications, the probability of creating a reciprocated link is negatively related to Ext $t_{i j v} . \beta_{\text {ext } 2}<0$ for $L A N D$ and CREDIT when $E x t_{i j v}^{i n}$ is considered, and for INPUT when Ext $t_{i j v}^{\text {out }}$ is taken into account (in the case of the latter, only significant at the $12 \%$ level). It is interesting that the effect is particularly pronounced in those networks where reciprocation is less prevalent (Table 11), a fact that may be related to endogenous preferences and cultural norms. ${ }^{15}$

\section{Conclusions}

A long tradition of anthropological studies have described the characteristics of primitive economies based on reciprocal exchanges, known as gift economies, and how this type of transactions tend to be reduced when more complex exchange mechanisms exist. This transformation process is formalized in the model introduced by Kranton (1996). Nevertheless, little rigorous empirical evidence has been provided to support the qualitative evidence and the predictions from the model. In order to fill this gap, the present study takes advantage of a unique dataset of social and economic networks collected in 60 rural Gambian villages to analyze the ways in which households with links outside the village (interpreted as a proxy for market connections) behave in the locally available exchange networks for land, labor, input and credit.

The main results, from econometric specifications at both household and dyadic level, provide evidence supporting the predictions of the transformation process. In particular, it is found that: (i) households with external economic links are less likely to be involved in economic interactions within the village (substitutability between internal and external exchanges); and (ii) households with external economic links are less likely to be involved in reciprocated exchanges with fellow villagers (reciprocation versus market hypothesis). In the case of the substitutability between internal and external exchanges, the results are mainly driven by within-network effects, given cross-networks coefficients are statistically insignificant (e.g. an external link in the network of inputs of production is a substitute of an internal link in the inputs exchange but this is not the case for the other economic exchange networks). In terms of reciprocation versus market, the analysis also provides evidence of within-network substitution, but jointly with some cross-networks effects. The results are robust to different econometric specifications and alternative methods to

\footnotetext{
${ }^{15}$ Given very small within household variation in terms of the partners, it is not possible to estimate Equation 8 using conditional logit.
} 
control for village and household level unobserved heterogeneity, but the effects are not always present for every network.

The findings suggest some important policy implications. The goal of many rural development programs is the integration of isolated communities into market transactions. In other words, using a network framework, there is an effort to create external links that connect currently missing markets. Nevertheless, often these programs fail, and, as suggested by theoretical models, this may be because the benefits of market transactions are not enough to abandon traditional means of exchange and production (de Janvry et al., 1991; Kranton, 1996). Therefore, it is necessary to consider the complexities of community exchanges in order to understand the effects of market-oriented interventions. For instance, von Braun and Webb (1989) and Carney and Watts (1990) have shown how in The Gambia many programs that attempted to increase agricultural productivity and cash crops production failed because the traditional distribution of land was not considered in the design. The results that I have presented suggest that the existence of external links is related to a decrease in the exchanges within the village, and particularly of reciprocated exchanges with fellow villagers. If policies oriented to the creation of external links are implemented, undesired effects, such as the reduction in community interactions and the isolation of villagers not willing to abandon the gift exchanging system, can be the source of new failed attempts of rural development.

The study of the transformation of rural societies using a network perspective have the potential to improve the understanding of the overall economic development process. Exploring if the results of the present contribution hold in other communities and improving data collection and analysis to overcome its limitations represent fruitful avenues for future research.

\section{References}

Banerjee, A., Chandrasekhar, A. G., Duflo, E. and Jackson, M. O. (2012). The Diffusion of Microfinance. NBER Working Papers 17743.

Barrett, C. B. (2008). Smallholder market participation: Concepts and evidence from eastern and southern Africa. Food Policy, 33 (4), 299-317.

Becker, S. O. and Ichino, A. (2002). Estimation of average treatment effects based on propensity scores. Stata Journal, 2 (4), 358-377.

Bellemare, M. F. and Barrett, C. B. (2006). An ordered tobit model of market participation: Evidence from Kenya and Ethiopia. American Journal of Agricultural Economics, 88 (2), 324-337.

Borgatti, S. P. (2005). Centrality and network flow. Social Networks, 27 (1), 55-71.

Bowles, S. (1998). Endogenous preferences: The cultural consequences of markets and other economic institutions. Journal of Economic Literature, 36 (1), 75-111.

Cameron, C., Gelbach, J. and Miller, D. (2011). Robust inference with multiway clustering. Journal of Business and Economic Statistics, 29 (2), 238-249. 
- and Windmeijer, F. (1997). An R-squared measure of goodness of fit for some common nonlinear regression models. Journal of Econometrics, 77 (2), 329-342.

Carney, J. and Watts, M. (1990). Manufacturing dissent: Work, gender and the politics of meaning in a peasant society. Africa: Journal of the International African Institute, 60 (2), 207-241.

Chamberlain, G. (1980). Analysis of covariance with qualitative data. Review of Economic Studies, 47 (1), 225-38.

Chavas, J.-P., Petrie, R. and Roth, M. (2005). Farm household production efficiency: Evidence from The Gambia. American Journal of Agricultural Economics, 87 (1), 160-179.

DE Janvry, A., FAfChamps, M. and Sadoulet, E. (1991). Peasant household behaviour with missing markets: Some paradoxes explained. Economic Journal, 101 (409), 1400-417.

Fafchamps, M. and Gubert, F. (2007). The formation of risk sharing networks. Journal of Development Economics, 83 (2), 326-350.

Gajigo, O. and Saineb, A. (2011). The effects of government policies on cereal consumption pattern change in the Gambia. Review of African Political Economy, 38 (130), 517-536.

Goetz, S. (1992). A selectivity model of household food marketing behavior in SubSaharan Africa. American journal of agricultural economics, 74, 444-452.

Henrich, J., Boyd, R., Bowles, S., Camerer, C., Fehr, E. and Gintis, H. (eds.) (2004). Foundations of Human Sociality: Economic Experiments and Ethnographic Evidence from Fifteen Small-Scale Societies. Oxford University Press.

-, Ensminger, J., McElreath, R., Barr, A., Barrett, C., Bolyanatz, A., Cardenas, J. C., Gurven, M., Gwako, E., Henrich, N., Lesorogol, C., MarLowe, F., Tracer, D. and Ziker, J. (2010). Markets, Religion, Community Size, and the Evolution of Fairness and Punishment. Science, 327, 1480-1484.

Hyde, L. (1983). The gift : imagination and the erotic life of property. New York, NY: Random House.

Jaimovich, D. (2011). Macrostructure and microstructure: Evidence from overlapping village networks in The Gambia. MPRA Paper 38932.

Key, N., Sadoulet, E. and De Janvry, A. (2000). Transactions costs and agricultural household supply response. American Journal of Agricultural Economics, 82 (2), 24559 .

Kranton, R. E. (1996). Reciprocal exchange: A self-sustaining system. American Economic Review, 86 (4), 830-51.

- and Minehart, D. F. (2001). A theory of buyer-seller networks. American Economic Review, 91 (3), 485-508. 
Malinowski, B. (1921). The primitive economics of the trobriand islanders. Economic Journal, 31 (121), 1-16.

- (ed.) (1922). Argonauts of the Western Pacific : an account of native enterprise and adventure in the archipelagos of Melanesian New Guinea. London, England: Routledge \& Kegan Paul.

Mauss, M. (1923). Essai sur le don: Forme et raison de l'échange dans les sociétés archaïques. Année sociologique 1923-1924.

Papke, L. E. and Wooldridge, J. M. (2008). Panel data methods for fractional response variables with an application to test pass rates. Journal of Econometrics, $145(1-2), 121-133$.

POLANYI, K. (1944). The great transformation: The political and economic origins of our time. New York, NY: Farrar and Rinehart.

Shipton, P. (1990). How Gambians save and what their strategies imply for international aid, World Bank Policy, research and external affairs working papers, WPS 395.

Swindell, K. (1978). Family farms and migrant labour: The strange farmers of The Gambia. Canadian Journal of African Studies / Revue Canadienne des Etudes Africaines, 12 (1), 3-17.

von Braun, J. and WebB, P. (1989). The impact of new crop technology on the agricultural division of labor in a West African setting. Economic Development and Cultural Change, 37 (3), 513-534.

WebB, P. (1989). Intrahousehold Decision-making and Resource Control: The Effects of Rice Commercialization in West Africa, international Food Policy Research Center, Working Papers on Commercialization of Agriculture and Nutrition. Number 3. 
Table 1: HOUSEHOLD DESCRIPTIVE STATISTICS

\begin{tabular}{lcccc}
\hline \hline Variable & Mean & Std. Dev. & Min & Max \\
\hline Household Size & HOUSEHOLD CHARACTERISTICS \\
\hline Age of household head & 12.67 & 11.40 & 1 & 400 \\
Female Household head & 51.70 & 15.54 & 15 & 100 \\
Formal Education & 0.06 & 0.25 & 0 & 1 \\
Compound head & 0.16 & 0.37 & 0 & 1 \\
Polygamous & 0.84 & 0.37 & 0 & 1 \\
Monogamous & 0.46 & 0.50 & 0 & 1 \\
Relatives in the village (\%) & 0.48 & 0.50 & 0 & 1 \\
Non Muslim & 0.09 & 0.09 & 0 & 0.73 \\
Ethnic minority & 0.04 & 0.19 & 0 & 1 \\
Workers in the household & 0.19 & 0.40 & 0 & 1 \\
Agricultural land (hectares) & 1.27 & 0.66 & 0 & 6 \\
Land per worker (hectares) & 8.06 & 21.22 & 0 & 400 \\
Income per capita (GMD) & 2.27 & 7.40 & 0 & 133 \\
Agricultural income (\% of total) & 3,514 & 4,735 & 43 & 125,000 \\
Emigrants & 0.12 & 0.24 & 0 & 1 \\
Cash crops sellers & 0.48 & 0.50 & 0 & 1 \\
Remittances receivers & 0.41 & 0.49 & 0 & 1 \\
\hline & 0.19 & 0.39 & 0 & 1 \\
\hline Alkalo & & VILLAGE ROLE & \\
Alkalo's relative & 0.02 & 0.14 & 0 & 1 \\
Alkalo's assistant & 0.35 & 0.48 & 0 & 1 \\
VDC member & 0.04 & 0.20 & 0 & 1 \\
Elders council member & 0.19 & 0.39 & 0 & 1 \\
Traditional healer & 0.19 & 0.39 & 0 & 1 \\
Griot (storyteller) & 0.20 & 0.40 & 0 & 1 \\
Imam & 0.01 & 0.12 & 0 & 1 \\
Marabout & 0.02 & 0.14 & 0 & 1 \\
\hline \hline
\end{tabular}

Note: Household-level descriptive statistics. 2,810 observations for each variable. A fully detailed description of the variables can be found in Jaimovich (2011). 


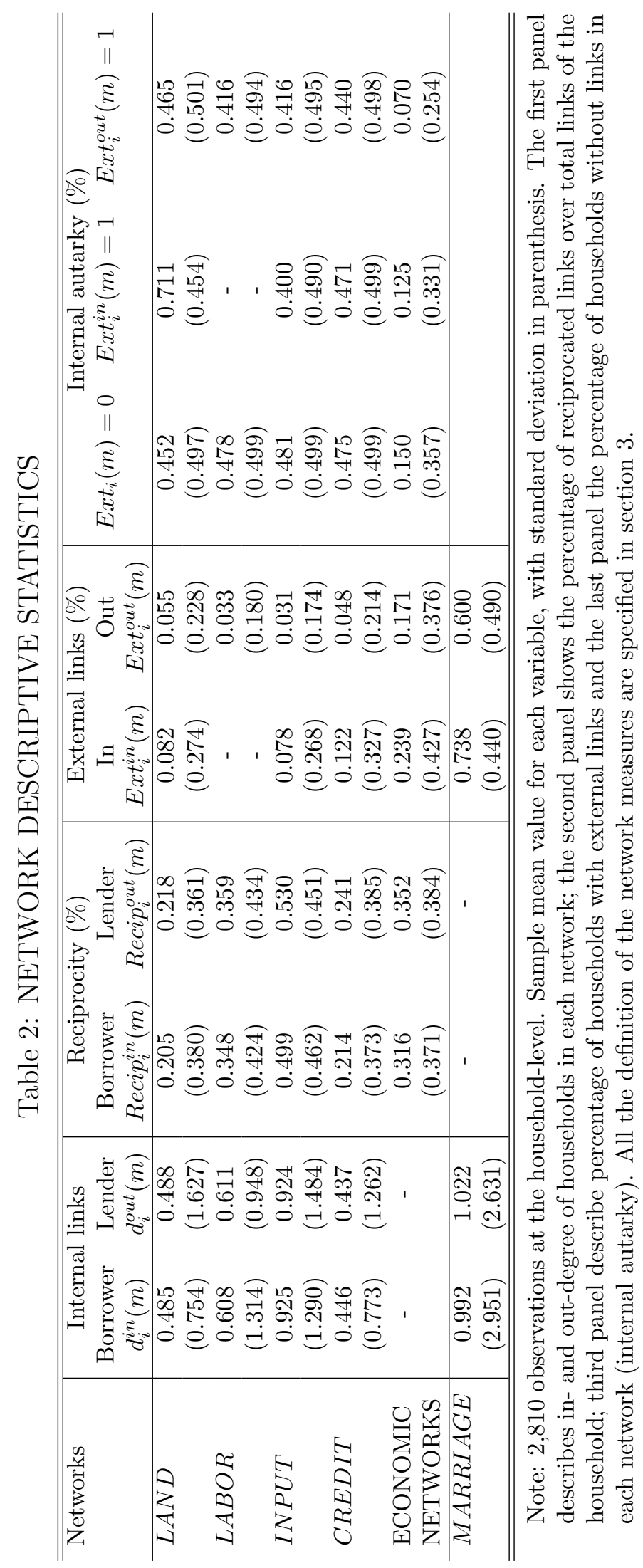




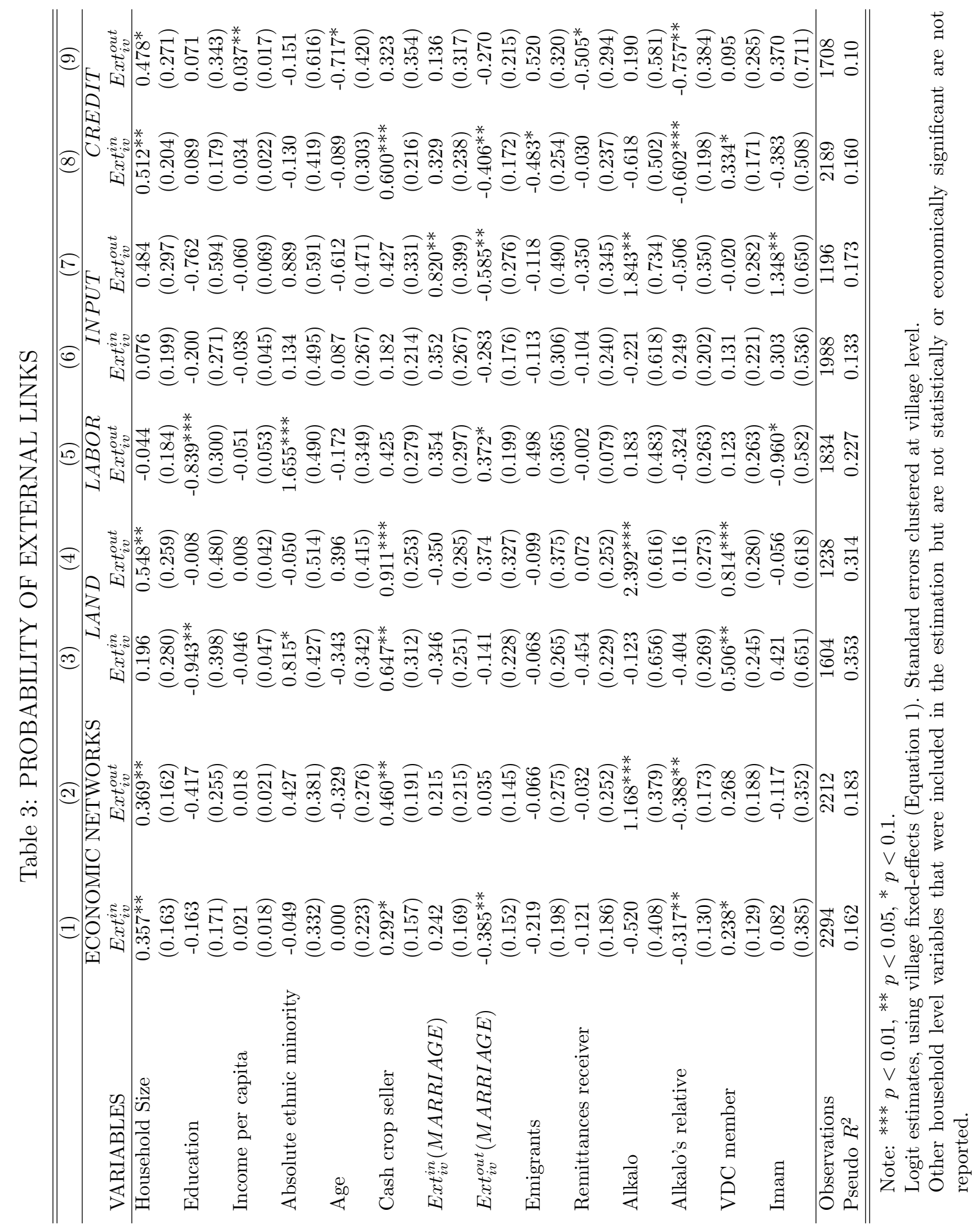




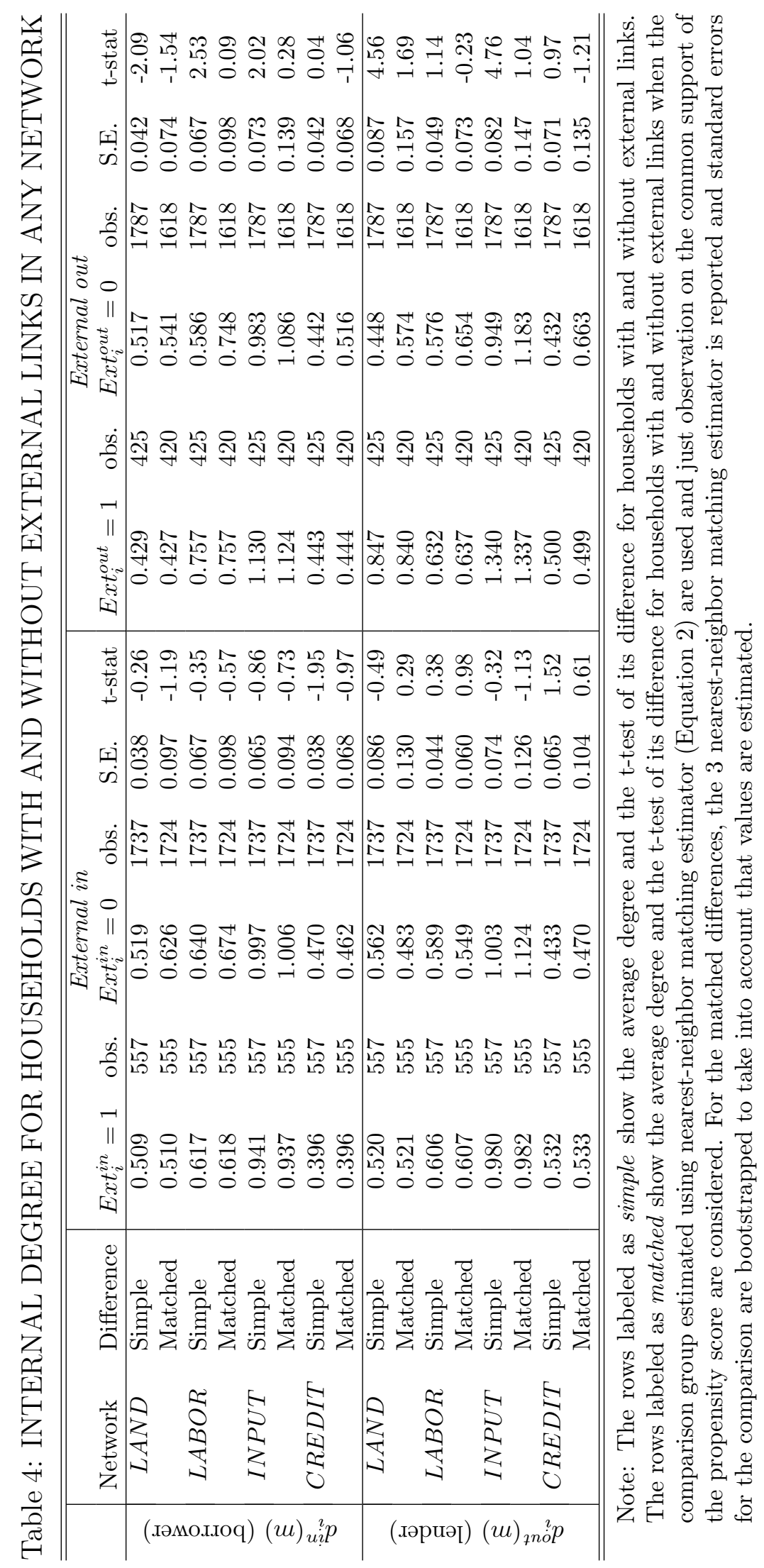




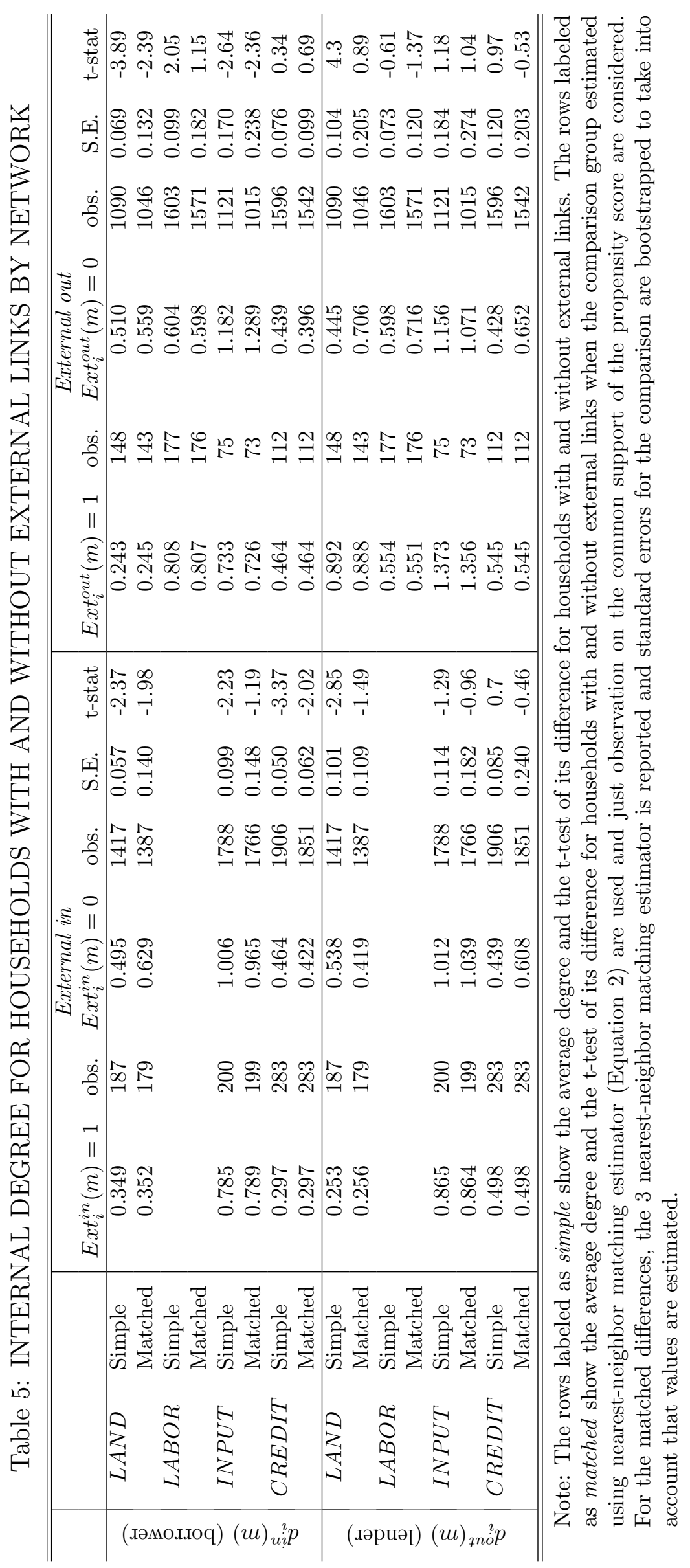




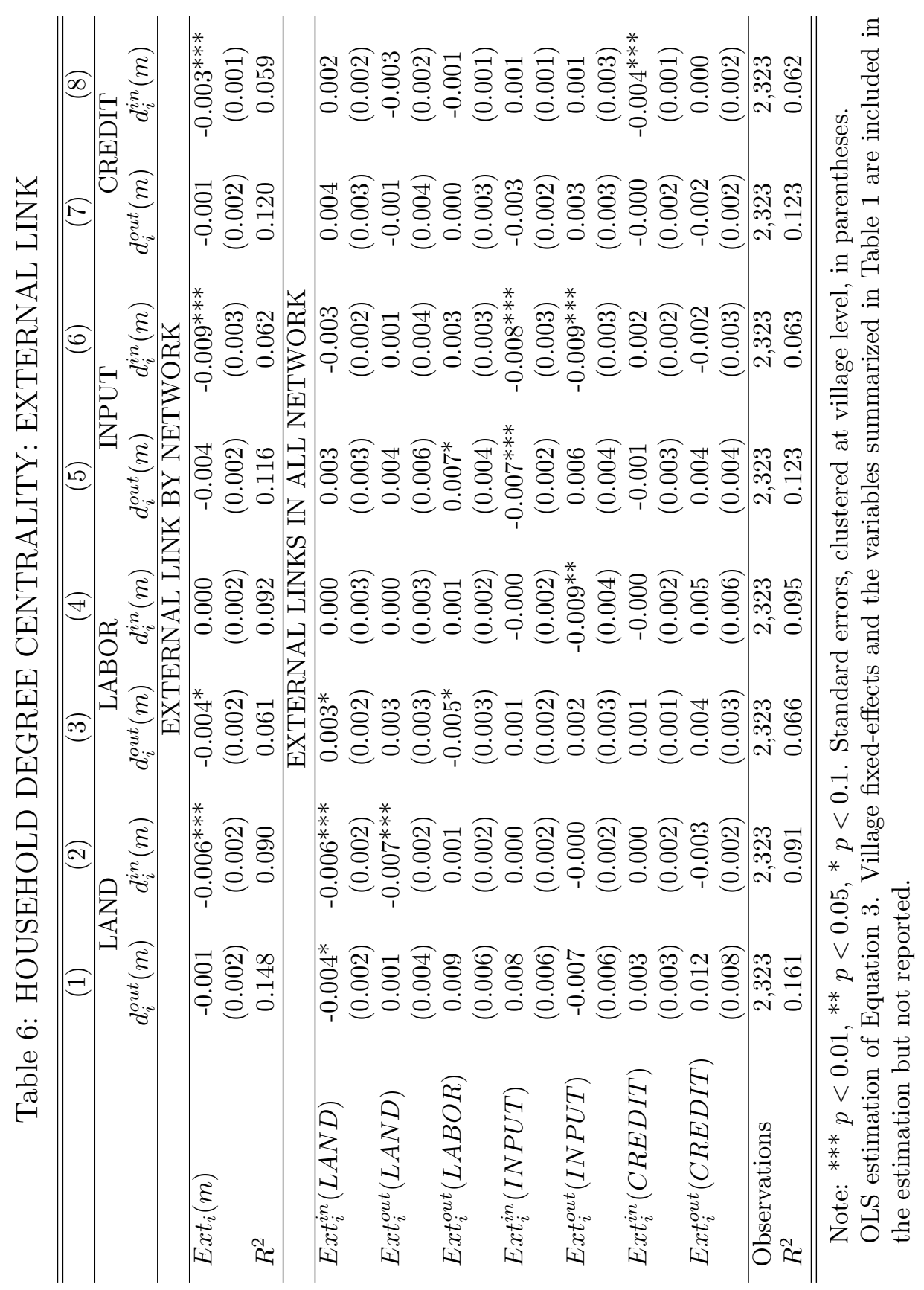




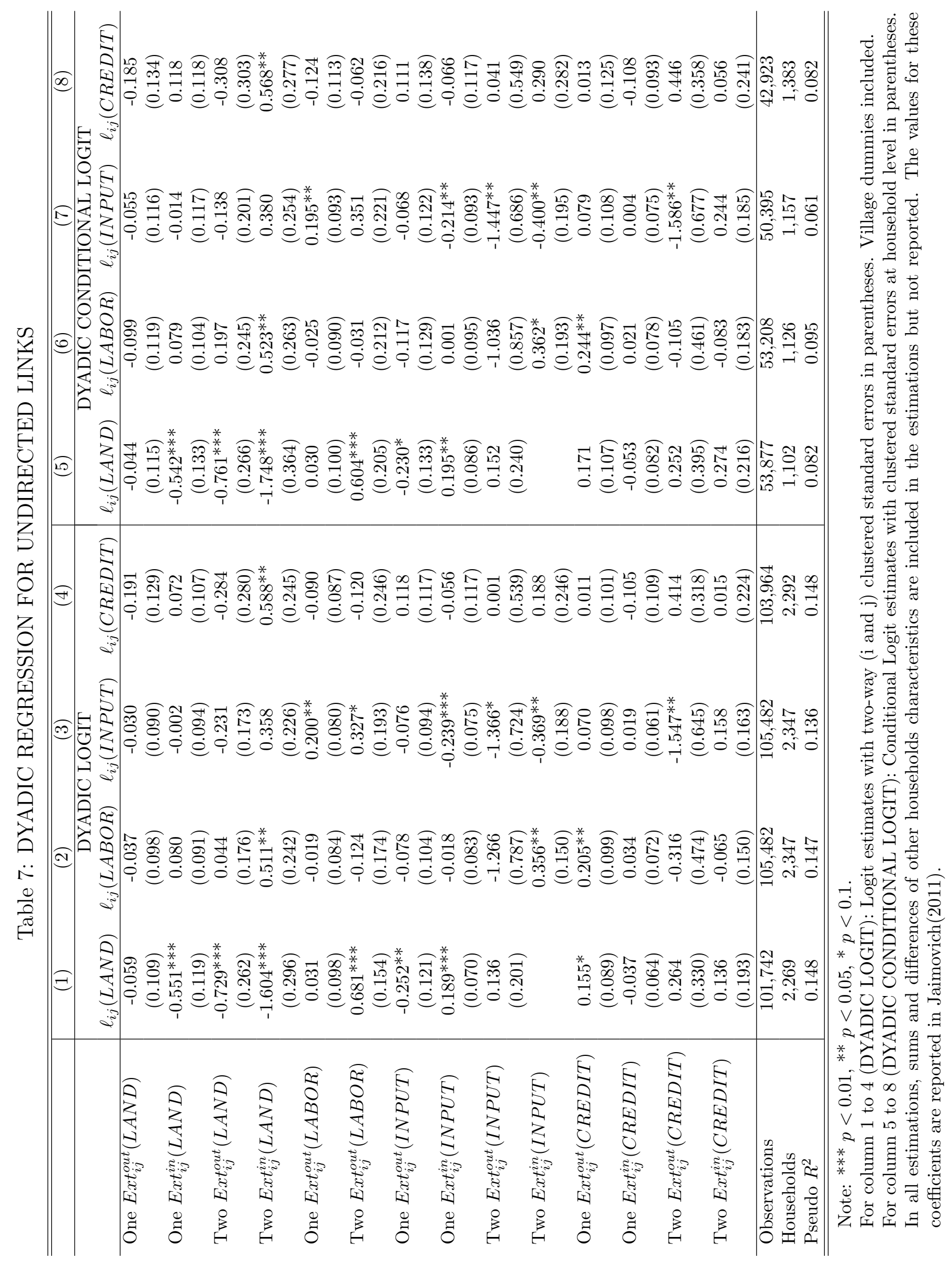




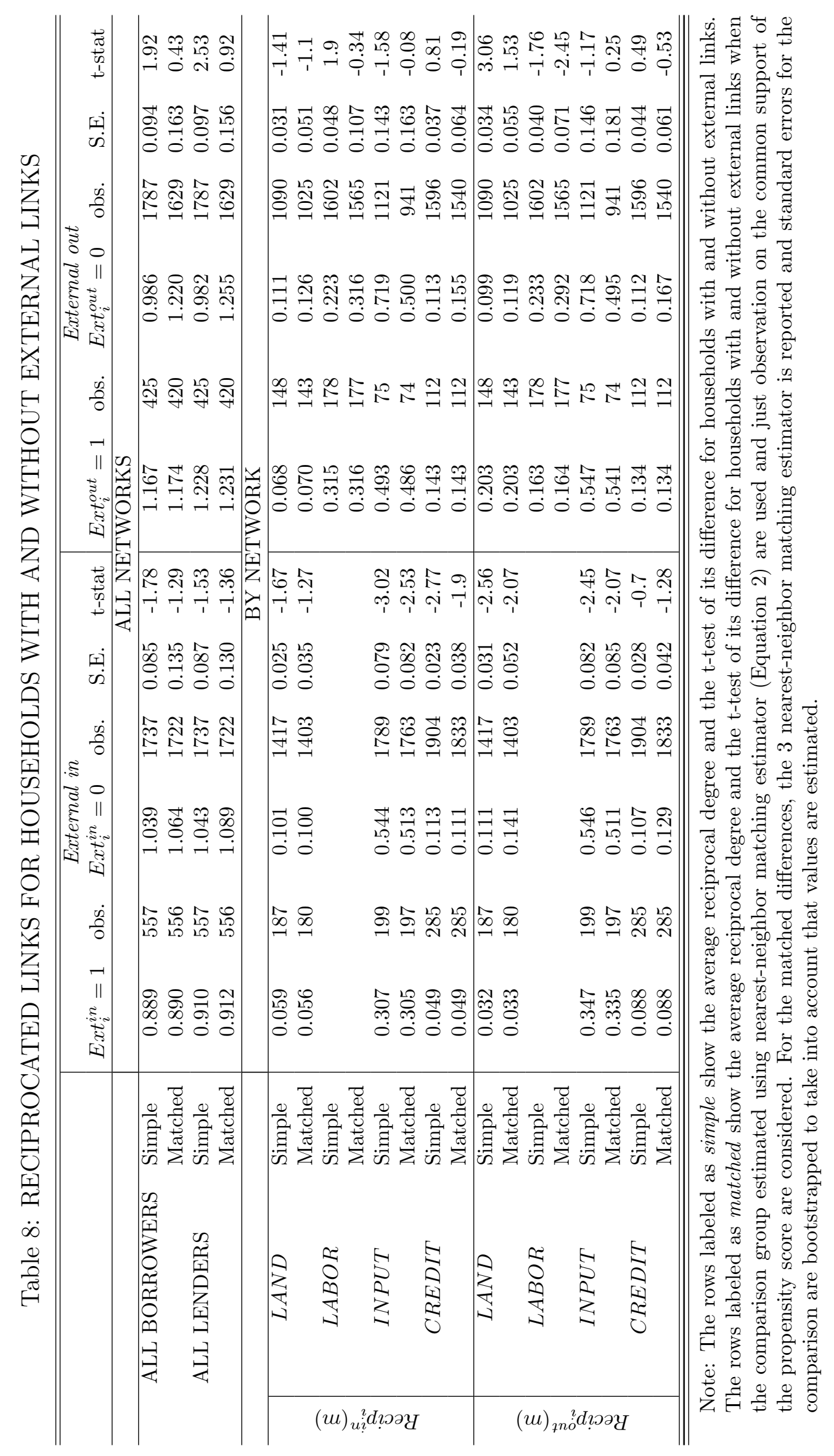




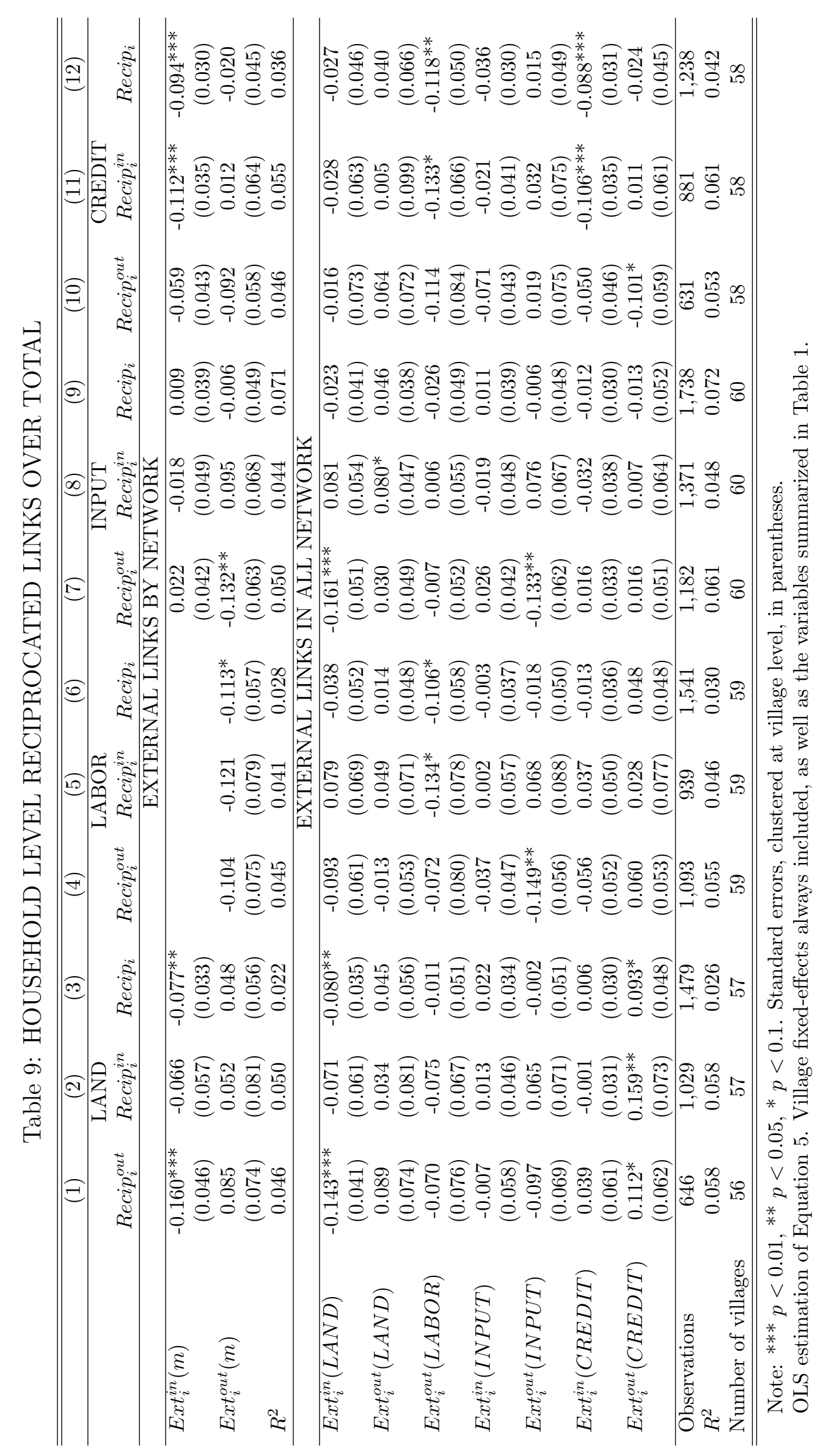


Table 10: LINKS SUMMARY: RECIPROCITY IN ALL ECONOMIC NETWORKS

\begin{tabular}{|c|c|c|c|c|c|c|}
\hline External links & \multicolumn{2}{|c|}{$\operatorname{Ext}_{i}(m)=0$} & \multicolumn{2}{|c|}{$\operatorname{Ext}_{i}^{i n}(m)=1$} & \multicolumn{2}{|c|}{$\operatorname{Ext}_{i}^{\text {out }}(m)=1$} \\
\hline Internal links & Borrow & Lend & Borrow & Lend & Borrow & Lend \\
\hline & \multicolumn{6}{|c|}{ LINKS WITH ALL VILLAGERS } \\
\hline Total links & 4815 & 4528 & 1764 & 1879 & 1128 & 1383 \\
\hline Reciprocated & $47.9 \%$ & $50.9 \%$ & $43.6 \%$ & $40.9 \%$ & $53.5 \%$ & $43.7 \%$ \\
\hline Non-reciprocated & $52.1 \%$ & $49.1 \%$ & $56.4 \%$ & $59.1 \%$ & $46.5 \%$ & $56.3 \%$ \\
\hline & \multicolumn{6}{|c|}{ LINKS WITH NON-FAMILY } \\
\hline Total links & 2889 & 2712 & 1012 & 1069 & 676 & 845 \\
\hline Reciprocated & $35.1 \%$ & $37.4 \%$ & $36.6 \%$ & $34.6 \%$ & $45.0 \%$ & $36.0 \%$ \\
\hline Non-reciprocated & $64.9 \%$ & $62.6 \%$ & $63.4 \%$ & $65.4 \%$ & $55.0 \%$ & $64.0 \%$ \\
\hline & \multicolumn{6}{|c|}{ LINKS WITH FAMILY } \\
\hline Total links & 1926 & 1816 & 752 & 810 & 452 & 538 \\
\hline Reciprocated & $67.0 \%$ & $71.1 \%$ & $56.3 \%$ & $51.8 \%$ & $66.4 \%$ & $55.8 \%$ \\
\hline Non-reciprocated & $33.0 \%$ & $28.9 \%$ & $43.7 \%$ & $48.2 \%$ & $33.6 \%$ & $44.2 \%$ \\
\hline
\end{tabular}

Note: Summary of all the links registered in the four economic networks ( LAND, LABOR, INPUT and CREDIT). Based on 2,810 households. 
Table 11: LINKS SUMMARY: RECIPROCITY BY NETWORK

\begin{tabular}{|c|c|c|c|c|c|c|}
\hline \multirow{2}{*}{$\begin{array}{l}\text { External links } \\
\text { Internal links }\end{array}$} & \multicolumn{2}{|c|}{$\operatorname{Ext}_{i}(m)=0$} & \multicolumn{2}{|c|}{$\operatorname{Ext}_{i}^{i n}(m)=1$} & \multicolumn{2}{|c|}{$\operatorname{Ext}_{i}^{\text {out }}(m)=1$} \\
\hline & Borrow & Lend & Borrow & Lend & Borrow & Lend \\
\hline & \multicolumn{6}{|c|}{$L A N D$} \\
\hline Total links & 1305 & 1228 & 71 & 49 & 38 & 137 \\
\hline Reciprocated with: & & & & & & \\
\hline$L A N D$ & $3.4 \%$ & $3.6 \%$ & $0.0 \%$ & $0.0 \%$ & $15.8 \%$ & $4.4 \%$ \\
\hline$L A B O R$ & $10.2 \%$ & $9.6 \%$ & $4.2 \%$ & $10.2 \%$ & $0.0 \%$ & $9.5 \%$ \\
\hline$I N P U T$ & $8.4 \%$ & $8.2 \%$ & $7.0 \%$ & $4.1 \%$ & $7.9 \%$ & $10.2 \%$ \\
\hline CREDIT & $3.1 \%$ & $3.7 \%$ & $7.0 \%$ & $0.0 \%$ & $5.3 \%$ & $1.5 \%$ \\
\hline \multirow[t]{2}{*}{ Non-reciprocated } & $74.9 \%$ & $74.8 \%$ & $81.7 \%$ & $85.7 \%$ & $71.1 \%$ & $74.5 \%$ \\
\hline & \multicolumn{6}{|c|}{$L A B O R$} \\
\hline Total links & 1664 & 1711 & & & 109 & 62 \\
\hline Reciprocated with: & & & & & & \\
\hline$L A N D$ & $7.1 \%$ & $7.8 \%$ & & & $16.5 \%$ & $4.8 \%$ \\
\hline$L A B O R$ & $11.6 \%$ & $11.3 \%$ & & & $2.8 \%$ & $4.8 \%$ \\
\hline$I N P U T$ & $20.3 \%$ & $20.0 \%$ & & & $12.8 \%$ & $14.5 \%$ \\
\hline CREDIT & $8.0 \%$ & $7.9 \%$ & & & $5.5 \%$ & $6.5 \%$ \\
\hline \multirow[t]{2}{*}{ Non-reciprocated } & $53.1 \%$ & $53.1 \%$ & & & $62.4 \%$ & $69.4 \%$ \\
\hline & \multicolumn{6}{|c|}{$I N P U T$} \\
\hline Total links & 2452 & 2396 & 183 & 184 & 61 & 125 \\
\hline Reciprocated with: & & & & & & \\
\hline$L A N D$ & $4.2 \%$ & $4.3 \%$ & $6.0 \%$ & $6.0 \%$ & $3.3 \%$ & $4.8 \%$ \\
\hline$L A B O R$ & $13.4 \%$ & $13.2 \%$ & $10.9 \%$ & $11.4 \%$ & $8.2 \%$ & $12.8 \%$ \\
\hline$I N P U T$ & $47.6 \%$ & $48.7 \%$ & $25.7 \%$ & $25.5 \%$ & $59.0 \%$ & $28.8 \%$ \\
\hline$C R E D I T$ & $5.9 \%$ & $6.3 \%$ & $3.8 \%$ & $3.8 \%$ & $11.5 \%$ & $2.4 \%$ \\
\hline \multirow[t]{2}{*}{ Non-reciprocated } & $28.9 \%$ & $27.5 \%$ & $53.6 \%$ & $53.3 \%$ & $18.0 \%$ & $51.2 \%$ \\
\hline & \multicolumn{6}{|c|}{$C R E D I T$} \\
\hline Total links & 1142 & 1046 & 94 & 173 & 60 & 83 \\
\hline Reciprocated with: & & & & & & \\
\hline$L A N D$ & $3.9 \%$ & $4.0 \%$ & $1.1 \%$ & $2.9 \%$ & $5.0 \%$ & $1.2 \%$ \\
\hline$L A B O R$ & $11.0 \%$ & $11.0 \%$ & $6.4 \%$ & $9.2 \%$ & $15.0 \%$ & $12.0 \%$ \\
\hline$I N P U T$ & $12.3 \%$ & $12.6 \%$ & $10.6 \%$ & $8.1 \%$ & $15.0 \%$ & $15.7 \%$ \\
\hline$C R E D I T$ & $2.8 \%$ & $3.1 \%$ & $1.1 \%$ & $0.6 \%$ & $1.7 \%$ & $1.2 \%$ \\
\hline Non-reciprocated & $69.9 \%$ & $69.3 \%$ & $80.9 \%$ & $79.2 \%$ & $63.3 \%$ & $69.9 \%$ \\
\hline
\end{tabular}

Note: Summary of all the links registered in the four economic networks (LAND, LABOR, INPUT and CREDIT). Based on 2,810 households. 
Table 12: DYADIC REGRESSION FOR RECIPROCATED LINKS

\begin{tabular}{|c|c|c|c|c|}
\hline & $(1)$ & $(2)$ & $(3)$ & $(4)$ \\
\hline & $\operatorname{Recip}_{i j}(L A N D)$ & $\operatorname{Recip}_{i j}(L A B O R)$ & $\operatorname{Recip}_{i j}(I N P U T)$ & $\operatorname{Recip}_{i j}(C R E D I T)$ \\
\hline \multirow[t]{2}{*}{ One $E x t_{i j}^{\text {out }}(L A N D)$} & 0.146 & 0.127 & 0.297 & 0.065 \\
\hline & $(0.393)$ & $(0.289)$ & $(0.240)$ & $(0.364)$ \\
\hline \multirow[t]{2}{*}{ One $E x t_{i j}^{i n}(L A N D)$} & -0.570 & -0.436 & 0.025 & -0.281 \\
\hline & $(0.351)$ & $(0.309)$ & $(0.242)$ & $(0.381)$ \\
\hline \multirow[t]{2}{*}{ Two $E_{x} t_{i j}^{\text {out }}(L A N D)$} & -0.519 & 0.469 & $0.776^{*}$ & 1.173 \\
\hline & $(0.896)$ & $(0.540)$ & $(0.420)$ & $(0.796)$ \\
\hline \multirow[t]{2}{*}{ Two $\operatorname{Ext}_{i j}^{i n}(L A N D)$} & $-2.074^{*}$ & -0.598 & -0.259 & -0.455 \\
\hline & $(1.237)$ & $(0.557)$ & $(0.562)$ & $(0.779)$ \\
\hline \multirow[t]{2}{*}{ One $\operatorname{Ext}_{i j}^{\text {out }}(L A B O R)$} & 0.323 & -0.001 & -0.168 & -0.169 \\
\hline & $(0.311)$ & $(0.239)$ & $(0.214)$ & $(0.309)$ \\
\hline \multirow[t]{2}{*}{ Two $\operatorname{Ext}_{i j}^{\text {out }}(L A B O R)$} & -0.485 & -0.054 & 0.065 & 0.022 \\
\hline & $(0.570)$ & $(0.655)$ & $(0.523)$ & $(0.795)$ \\
\hline \multirow[t]{2}{*}{ One $\operatorname{Ext}_{i j}^{\text {out }}(I N P U T)$} & -0.621 & -0.252 & -0.412 & -0.027 \\
\hline & $(0.420)$ & $(0.300)$ & $(0.273)$ & $(0.393)$ \\
\hline \multirow[t]{2}{*}{ One $E x t_{i j}^{i n}(I N P U T)$} & -0.036 & $-0.492^{*}$ & 0.133 & $-0.528^{*}$ \\
\hline & $(0.320)$ & $(0.276)$ & $(0.222)$ & $(0.315)$ \\
\hline \multirow[t]{2}{*}{ Two $E x t_{i j}^{i n}(I N P U T)$} & $1.358^{* *}$ & -0.578 & -0.567 & 0.057 \\
\hline & $(0.655)$ & $(0.643)$ & $(0.589)$ & $(0.731)$ \\
\hline \multirow[t]{2}{*}{ One $\operatorname{Ext}_{i j}^{\text {out }}(C R E D I T)$} & 0.392 & 0.309 & -0.143 & 0.029 \\
\hline & $(0.346)$ & $(0.244)$ & $(0.240)$ & $(0.369)$ \\
\hline \multirow[t]{2}{*}{ One $\operatorname{Ext}_{i j}^{i n}(C R E D I T)$} & 0.120 & -0.098 & -0.022 & $-0.775^{* *}$ \\
\hline & $(0.275)$ & $(0.205)$ & $(0.168)$ & $(0.305)$ \\
\hline \multirow[t]{2}{*}{ Two $E x t_{i j}^{\text {out }}(C R E D I T)$} & -0.098 & -0.130 & & -1.127 \\
\hline & $(1.047)$ & $(1.089)$ & & $(1.277)$ \\
\hline \multirow[t]{2}{*}{ Two $\operatorname{Ext}_{i j}^{i n}(C R E D I T)$} & 0.317 & 0.428 & -0.171 & -0.538 \\
\hline & $(0.539)$ & $(0.522)$ & $(0.511)$ & $(0.707)$ \\
\hline Observations & 1006 & 1162 & 1561 & 872 \\
\hline Households & 704 & 780 & 972 & 575 \\
\hline PseudoR ${ }^{2}$ & 0.270 & 0.217 & 0.317 & 0.304 \\
\hline
\end{tabular}

Note: ${ }^{* * *} p<0.01,{ }^{* *} p<0.05,{ }^{*} p<0.1$. Two-way $(i$ and $j$ ) clustered standard errors in parentheses. Logit estimates. Village dummies and other sums and differences of characteristics that were not statistically significant or have limited interest were included in the estimations but their associated coefficients are not reported. 


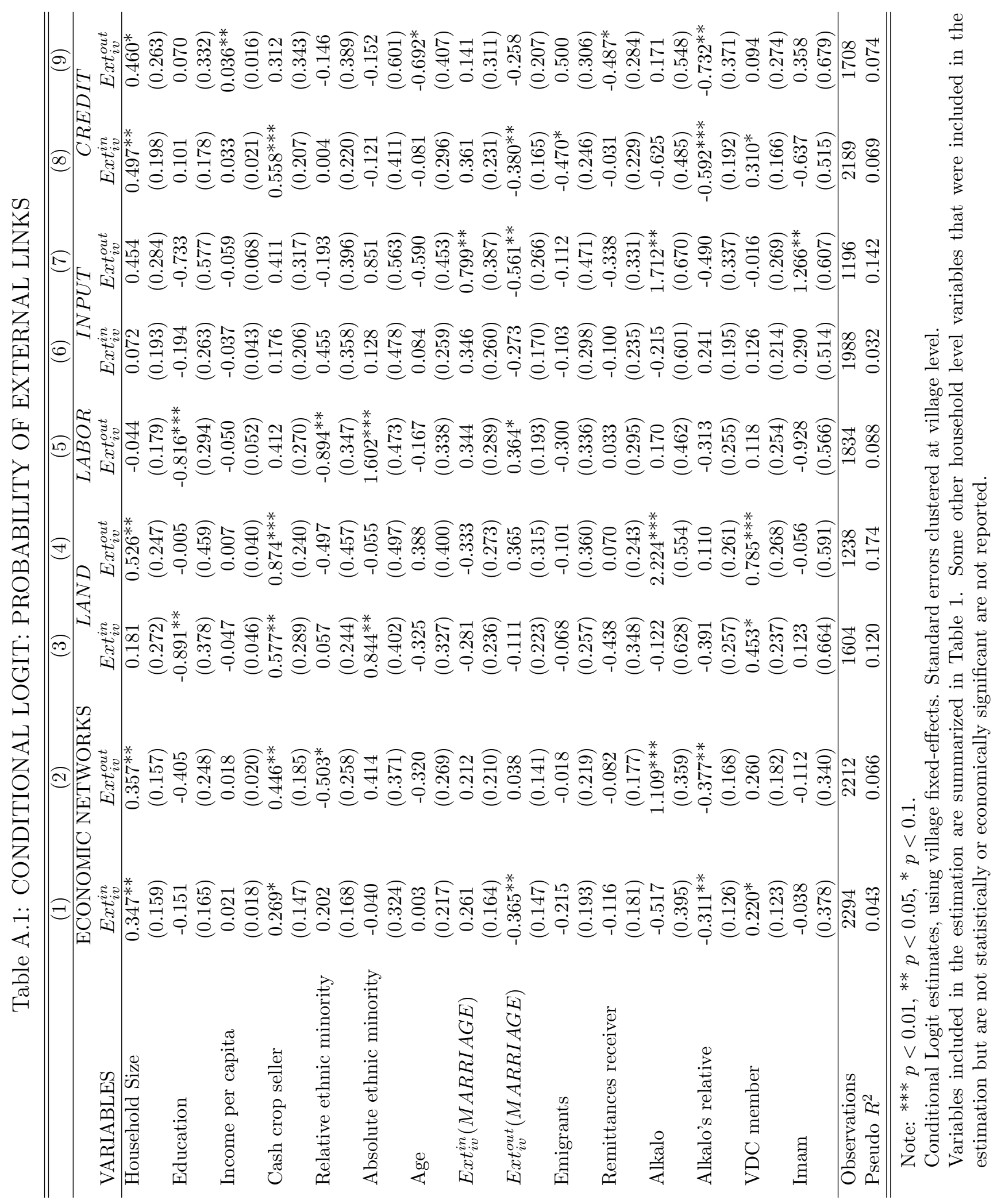


Table A.2: INTERNAL DEGREE FOR HOUSEHOLDS WITH AND WITHOUT EXTERNAL LINKS BY NETWORK (Difference in degree for networks different than the one with external link. Only matched samples)

\begin{tabular}{|c|c|c|c|c|c|c|c|}
\hline & \multicolumn{3}{|c|}{ External in } & \multicolumn{3}{|c|}{ External out } \\
\hline & & Degree difference & S.E. & t-stat & Degree difference & S.E. & t-stat \\
\hline & & \multicolumn{6}{|c|}{$\operatorname{Ext}_{i}(L A N D)$} \\
\hline \multirow{3}{*}{ 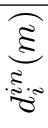 } & $L A B O R$ & 0.142 & 0.156 & 0.91 & -0.156 & 0.170 & -0.92 \\
\hline & $I N P U T$ & -0.208 & 0.147 & -1.42 & -0.266 & 0.214 & -1.24 \\
\hline & CREDIT & -0.027 & 0.105 & -0.25 & -0.023 & 0.090 & -0.26 \\
\hline \multirow{3}{*}{ 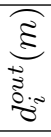 } & $L A B O R$ & 0.180 & 0.113 & 1.6 & 0.054 & 0.127 & 0.42 \\
\hline & $I N P U T$ & 0.165 & 0.173 & 0.95 & -0.051 & 0.239 & -0.21 \\
\hline & $C R E D I T$ & 0.059 & 0.214 & 0.27 & 0.033 & 0.144 & 0.23 \\
\hline \multirow{4}{*}{ 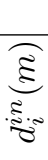 } & & \multicolumn{6}{|c|}{$\operatorname{Ext}_{i}(L A B O R)$} \\
\hline & $L A N D$ & & & & 0.008 & 0.089 & 0.09 \\
\hline & $I N P U T$ & & & & 0.004 & 0.166 & 0.02 \\
\hline & CREDIT & & & & -0.076 & 0.082 & -0.92 \\
\hline \multirow{3}{*}{ 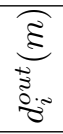 } & $L A N D$ & & & & 0.585 & 0.300 & 1.95 \\
\hline & $I N P U T$ & & & & 0.261 & 0.175 & 1.49 \\
\hline & $C R E D I T$ & & & & -0.271 & 0.161 & -1.68 \\
\hline \multirow{4}{*}{ 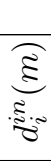 } & & \multicolumn{6}{|c|}{$\operatorname{Ext}_{i}(I N P U T)$} \\
\hline & $L A N D$ & -0.044 & 0.079 & -0.55 & -0.017 & 0.096 & -0.18 \\
\hline & $L A B O R$ & -0.044 & 0.146 & -0.3 & -0.062 & 0.145 & -0.43 \\
\hline & CREDIT & 0.037 & 0.062 & 0.59 & -0.056 & 0.104 & -0.54 \\
\hline \multirow{3}{*}{ 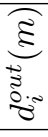 } & $L A N D$ & 0.407 & 0.265 & 1.53 & -0.005 & 0.241 & -0.02 \\
\hline & $L A B O R$ & 0.040 & 0.082 & 0.49 & -0.087 & 0.133 & -0.65 \\
\hline & CREDIT & -0.030 & 0.128 & -0.24 & -0.037 & 0.198 & -0.18 \\
\hline \multirow{4}{*}{ 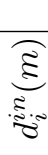 } & & \multicolumn{6}{|c|}{$\operatorname{Ext}_{i}(C R E D I T)$} \\
\hline & $L A N D$ & -0.004 & 0.050 & -0.08 & -0.158 & 0.090 & -1.76 \\
\hline & $L A B O R$ & 0.002 & 0.085 & 0.02 & 0.146 & 0.189 & 0.77 \\
\hline & CREDIT & 0.101 & 0.084 & 1.21 & -0.051 & 0.183 & -0.28 \\
\hline \multirow{3}{*}{ 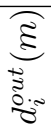 } & $L A N D$ & 0.108 & 0.115 & 0.95 & 0.750 & 0.466 & 1.61 \\
\hline & $L A B O R$ & 0.031 & 0.058 & 0.53 & 0.158 & 0.129 & 1.22 \\
\hline & CREDIT & 0.018 & 0.095 & 0.19 & 0.190 & 0.209 & 0.91 \\
\hline
\end{tabular}

Note: Difference in the average degree and its t-test for households with and without external links when the comparison group estimated using nearest-neighbor matching estimator (Equation 2) are used and just observation on the common support of the propensity score are considered. For the matched differences, the 3 nearest-neighbor matching estimator is reported and standard errors for the comparison are bootstrapped to take into account that values are estimated. 


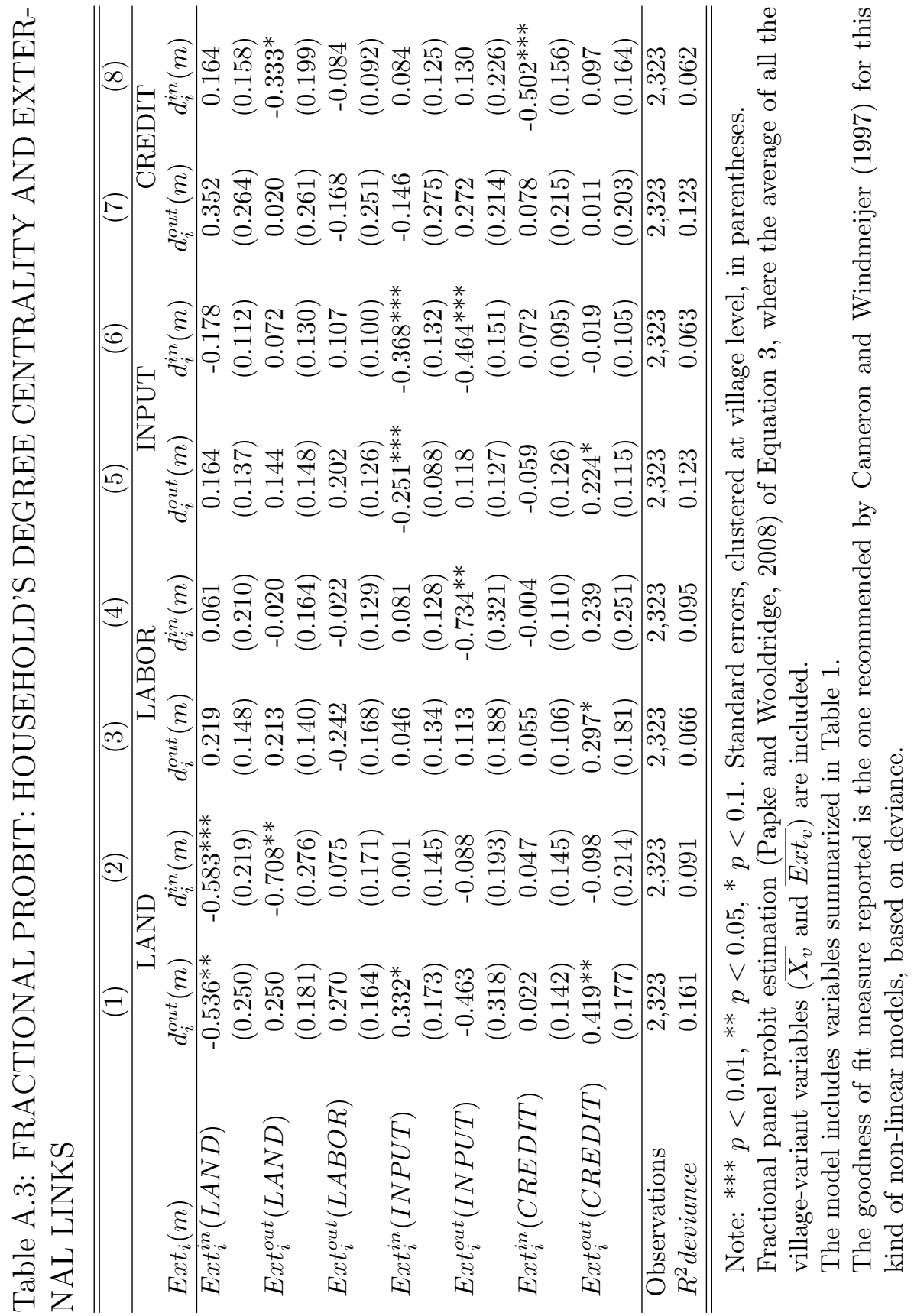


Table A.4: RECIPROCATED LINKS FOR HOUSEHOLDS WITH AND WITHOUT EXTERNAL LINKS BY NETWORK (Difference in reciprocaldegree for networks different than the one with external link. Only matched samples)

\begin{tabular}{|c|c|c|c|c|c|c|c|}
\hline & \multicolumn{3}{|c|}{ External in } & \multicolumn{3}{|c|}{ External out } \\
\hline & & Degree difference & S.E. & t-stat & Degree difference & S.E. & t-stat \\
\hline & & \multicolumn{6}{|c|}{$\operatorname{Ext}_{i}(L A N D)$} \\
\hline \multirow{3}{*}{ 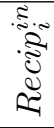 } & $L A B O R$ & 0.030 & 0.085 & 0.35 & 0.107 & 0.092 & 1.16 \\
\hline & $I N P U T$ & 0.002 & 0.135 & 0.01 & 0.168 & 0.160 & 1.05 \\
\hline & CREDIT & -0.015 & 0.048 & -0.31 & -0.016 & 0.050 & -0.33 \\
\hline \multirow{3}{*}{ 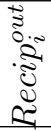 } & $L A B O R$ & 0.000 & 0.065 & 0 & 0.047 & 0.072 & 0.65 \\
\hline & $I N P U T$ & 0.026 & 0.143 & 0.18 & 0.107 & 0.163 & 0.66 \\
\hline & CREDIT & 0.048 & 0.058 & 0.83 & 0.089 & 0.066 & 1.34 \\
\hline & & \multicolumn{6}{|c|}{$\operatorname{Ext}_{i}(L A B O R)$} \\
\hline \multirow{3}{*}{ 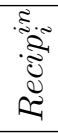 } & $L A N D$ & & & & -0.041 & 0.039 & -1.07 \\
\hline & $I N P U T$ & & & & 0.128 & 0.126 & 1.02 \\
\hline & CREDIT & & & & -0.075 & 0.044 & -1.72 \\
\hline \multirow{3}{*}{ 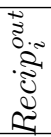 } & $L A N D$ & & & & 0.077 & 0.070 & 1.1 \\
\hline & $I N P U T$ & & & & 0.124 & 0.130 & 0.96 \\
\hline & CREDIT & & & & -0.032 & 0.057 & -0.56 \\
\hline & & \multicolumn{6}{|c|}{$\operatorname{Ext}_{i}(I N P U T)$} \\
\hline \multirow{3}{*}{ 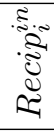 } & $L A N D$ & 0.015 & 0.032 & 0.48 & -0.018 & 0.052 & -0.35 \\
\hline & $L A B O R$ & 0.012 & 0.060 & 0.2 & 0.032 & 0.072 & 0.44 \\
\hline & CREDIT & -0.061 & 0.031 & -1.94 & -0.063 & 0.044 & -1.42 \\
\hline \multirow{3}{*}{ 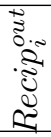 } & $L A N D$ & 0.047 & 0.058 & 0.81 & -0.117 & 0.056 & -2.08 \\
\hline & $L A B O R$ & -0.064 & 0.044 & -1.45 & -0.072 & 0.060 & -1.2 \\
\hline & $C R E D I T$ & -0.051 & 0.038 & -1.34 & 0.036 & 0.063 & 0.57 \\
\hline & & \multicolumn{6}{|c|}{$\operatorname{Ext}_{i}(C R E D I T)$} \\
\hline \multirow{3}{*}{ 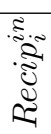 } & $L A N D$ & 0.021 & 0.026 & 0.81 & -0.039 & 0.041 & -0.95 \\
\hline & $L A B O R$ & 0.056 & 0.052 & 1.07 & 0.128 & 0.108 & 1.19 \\
\hline & CREDIT & -0.057 & 0.090 & -0.63 & 0.104 & 0.152 & 0.69 \\
\hline \multirow{3}{*}{ 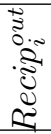 } & $L A N D$ & 0.058 & 0.041 & 1.43 & 0.179 & 0.091 & 1.97 \\
\hline & $L A B O R$ & -0.025 & 0.039 & -0.62 & -0.030 & 0.072 & -0.41 \\
\hline & CREDIT & -0.033 & 0.093 & -0.35 & 0.185 & 0.159 & 1.16 \\
\hline
\end{tabular}

Note: Difference in the average reciprocal degree and its t-test for households with and without external links when the comparison group estimated using nearest-neighbor matching estimator (Equation 2) are used and just observation on the common support of the propensity score are considered. For the matched differences, the 3 nearestneighbor matching estimator is reported and standard errors for the comparison are bootstrapped to take into account that values are estimated. 


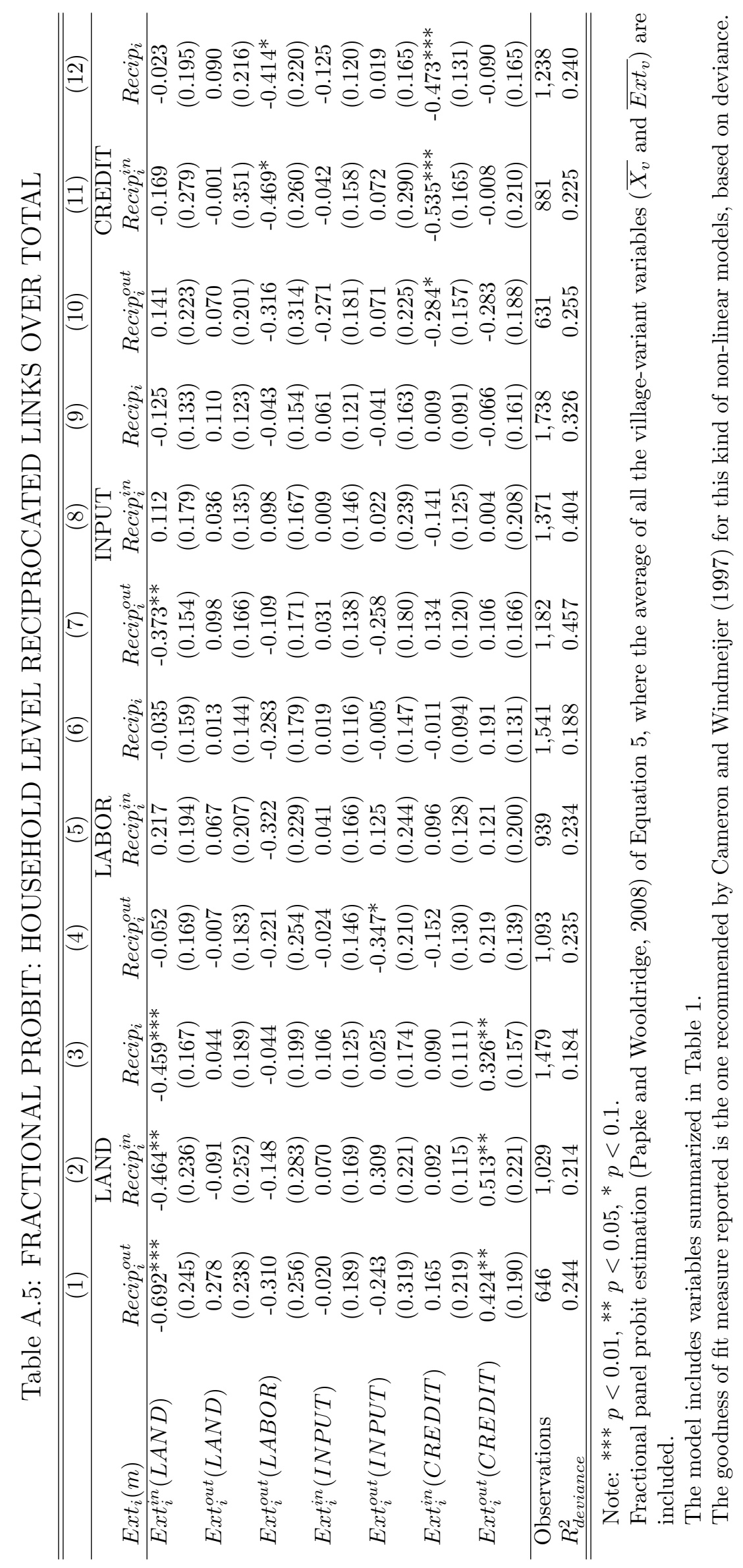

